\title{
New Method with Experimental Validation for Power Transmission Process Analysis on Herringbone Gear Train System
}

\author{
Wang Feng and Xu Xing \\ Automotive Engineering Research Institute, JiangSu University (212013), Zhen Jiang, China.
}

\author{
Fang Zong-de \\ School of Mechanical Engineering, Northwestern Polytechnical University (710072), Xian, China.
}

(Received 1 February 2016; accepted 23 May 2016)

To analyse the power transmission process of herringbone gear train system supported by rolling element bearings more accurately, meshing stiffness calculation method is firstly developed through tooth load contact analysis. The model of mesh impact force and the approach to calculate the equivalent friction torque coefficient in mixed elastohydrodynamic lubrication state are sequentially derived. The twelve-degree-of-freedom herringbone gear vibration model is finally established. Upon the consideration of different supporting ways between pinion and gear shaft, dynamic loads on support bearings are calculated separately. Based on rolling element bearing dynamic model and internal load distribution on bearings, comprehensive analysis of the vibration transmission process in meshing gear pair, rolling element bearings, and internal walls of gearbox bearing holes is conducted. Under the real dynamic load boundary condition, harmonic response and transient response of gearbox are obtained correspondingly. To evaluate the proposed model approach, a rolling element bearings support herringbone gear system is adopted to do real closed power flow vibration test. Simulation and experimental results show that the theoretical analysis in this paper is scientific and reasonable to calculate the dynamic load transfer process, and the maximum relative deviation between the theoretical results and the experimental data is less than $15 \%$.

\section{INTRODUCTION}

Herringbone gear sets, also known as double helical gear drives, are commonly used in transmission systems of marine, aerospace and other industrial equipment. They offer numerous advantages over general parallel-axis gear trains (i.e. helical gear and spur gear) including high bearing capacity, smooth transmission and small axial load. Most common examples of herringbone gear sets can be found in ship transmissions, jet engines, and helicopter drive trains. Dynamic loads between gear teeth are unavoidable in herringbone gear transmission, and it will also cause vibration of bearing and gearbox. ${ }^{1-3}$ Dynamic analysis is the first step to solve the noise and vibration problems in the herringbone gear systems. ${ }^{4}$ Owing to its widespread use in modern industry, dynamic health monitoring and early fault detection have attracted intensive investigations. ${ }^{5}$ Therefore, a reasonable and reliable dynamic transmission model needs to be put forward to describe noise and kinetic quality of herringbone gear systems.

Dynamic characteristics of gear pairs and gearbox have attracted increasing research efforts over the years. Huang and $\mathrm{Liu}^{6}$ treated a spur gear tooth as a variable cross-section Timoshenko beam to construct a dynamic model; dynamic responses of a single tooth and a gear pair were investigated. With the development of nonlinear dynamics, Theodossiades and Natsiavas ${ }^{7}$ investigated dynamics of a gear-pair system involving backlash, and several types of periodic steady state response were identified by employing suitable methodologies. Based on the research of Shabaneh and $\mathrm{Zu}^{8}{ }^{8}$ Kang and $\mathrm{Hsu}^{9}$ presented a hybrid method to study the dynamic behaviours of a gear-rotor system with viscoelastic supports under effects of the residual shaft bow. Dynamic characteristic analysis of gearbox is also important for further mastering the stability of whole transmission system. Li et al. ${ }^{10}$ simulated dynamical behaviour of a speed-increase gearbox by using the finite element (FE) method. Dbrowski 11 developed a multi-body dynamics model of the gears by MSC ADAMS software, and the simulations were conducted under different operation conditions. However, these studies did not establish a practical model to describe the whole vibration transfer process about gear transmission system. In general, there are two types of vibration transmitting analysis methods commonly used for gear system. The first one builds the complete FE model that include gear pairs, shafts, bearings and gearbox to simulate with initial boundary conditions. ${ }^{12-14}$ The other one only set up a gearbox FE model, and calculates dynamic loads of each bearing hole through lumped mass method. ${ }^{15-18}$ The former method obviously will bring high computational cost and great difficulty in FE grid meshing. And some unique factors of meshing gears such as corner mesh impact cannot be obtained by simulation using general FE software. By contrast, the latter is relatively scientific and reasonable due to taking account both of the efficiency and precision. Generally, this type method needs to establish a precise vibration transfer model, but the existing models are much simplified, for example, the influences of inner ring, roller, and outer ring were neglected, the results with such simplification may not be of engineering significance. So one comprehensive approach which considers vibration transfer process from meshing teeth to rolling element bearings as well as gearbox urgently needs to be pro- 
posed.

The main contribution of this study is developing a relatively better method to analyse the vibration transfer process of herringbone gear system. And it is organized as follows: The first segment aims at reviewing the published literatures on the modelling of the gear pair and gearbox, especially the vibration noise transmission analysis. Upon the consideration of the time-varying meshing stiffness, corner mesh impact, and equivalent friction torque coefficient excitations, the herringbone gear vibration model supported with rolling element bearings is derived in Section 2. And the lumped mass model of rolling element bearings and the gearbox FE model additional including lubrication oil are developed to quantitatively describe vibration transmissibility in Section 3 and Section 4. Then, the experimental results and discussions about the vibration acceleration of the herringbone gear system are exhibited in Section 5 which is followed by conclusion in Section 6 .

\section{DYNAMIC MODEL ANALYSIS OF HERRINGBONE GEAR SYSTEM}

\subsection{Internal Excitations of Herringbone Gear}

The herringbone gear tooth meshing vibration of transmission system can be induced by many factors, and the main excitation factors are time-varying meshing stiffness excitation, ${ }^{31}$ meshing impact force excitation, and tooth surface friction excitation. $^{4}$

\subsubsection{Time-varying meshing stiffness}

Loaded tooth contact analysis technology of helical gear was systematically proposed by ZHANG and FANG ${ }^{19}$ in 1999 . On this basis, the herringbone gear model for tooth contact analysis under load is shown in Fig. 1, where every two pairs of teeth, denoted by $I, I I$ and $I I I, I V$, are in contact at a specific instant among the meshing cycle. The tooth surface curve in the Fig. 1 is in the normal plane along the relative principal direction. And $i k(k=I, I I, I I I, I V)$ denotes the contact point, $j k$ denotes a point along the relative principal direction. Before the tooth deformation occurs, the clearance between a pair of contacting tooth surfaces along the relative principal direction can be determined by a column vector $[w]_{k}$.

Under load $P$, the driving gear goes through an approach $\mathrm{Z}$ and the contact load becomes distributed due to tooth deformation. The state of force balance after deformation can be described by the following equations:

$$
\begin{gathered}
{[F]_{k}[p]_{k}+[w]_{k}=[Z]+[d]_{k}, \quad k=I, I I, I I I, I V} \\
\left\{\begin{array}{l}
\sum_{j=1}^{n} p_{j \mathrm{I}}+\sum_{j=1}^{n} p_{j \mathrm{II}}=P_{L} \\
\sum_{j=1}^{n} p_{j I I I}+\sum_{j=1}^{n} p_{j I V}=P_{R} \\
P_{L}+P_{R}=P
\end{array}\right.
\end{gathered}
$$

$$
\left\{\begin{array}{lll}
p_{j k}>0 & \text { for } & d_{j k}=0 \\
d_{j k}>0 & \text { for } & p_{j k}=0
\end{array}\right.
$$

where, matrix $[p]_{k}$ is the contact load matrix; matrix $[d]_{k}$ is the final tooth clearance matrix; matrix $[F]_{k}$ is the flexibility matrix. Axial force of two helical gear pairs cannot completely offset because of the errors of manufacture and installation in the practical transmission, so the pinion is generally installed in the form of axial floating installation. The installation structure diagram of a herringbone gear system is depicted in Fig. 2.

In order to obtain the force balanced state $\left(P_{L}=P_{R}\right)$ of herringbone gear system, the axial movement is superimposed into the tooth clearance matrix $[w]_{k}$ as shown in Eq. (2).

$$
\left\{\begin{array}{l}
{\left[w^{\prime}\right]_{k}=[w]_{k} \pm\left[\varepsilon_{n}\right] \ldots k=I, I I} \\
{\left[w^{\prime}\right]_{k}=[w]_{k} \mp\left[\varepsilon_{n}\right] \ldots k=I I I, I V}
\end{array} ;\right.
$$

where $\left[\epsilon_{n}\right]$ is tiny displacement matrix along the principal direction of contact tooth pair; $\left[w^{\prime}\right]_{k}$ is the final tooth clearance matrix which considers axial displacement. Considering the axial movement of pinion, the loaded tooth contact analysis model of herringbone gear is solved from the nonlinear programming problem for each contact position.

The elastic deformation including bending, shear, and teeth contact deformation is commonly caused by tooth surface load, and the ability to resist this elastic deformation is called single tooth meshing stiffness. ${ }^{8}$ In order to get the meshing stiffness, normal contact deformation along the principal direction of tooth pair is calculated by loaded tooth contact analysis (LTCA) technology of herringbone gear. Fig. 3 is the detailed process of meshing stiffness calculation method based on LTCA.

\subsubsection{Corner mesh impact considerations with syn- thetic pitch errors due to meshin}

In the gear meshing process, "meshing synthetic pitch errors" occur due to transmission error and tooth deformation under load, and corner mesh impact is unavoidable in teeth engaging in and out processes because the actual contact point deviates from the theoretical meshing direction. ZHOU and $\mathrm{TANG}^{20}$ perform the method of "tooth deformation load process" to analyse the characteristics of corner meshing impact. For the detailed derivation of the impact location and impact velocity refer to reference. ${ }^{20}$ The impact model considering teeth contact ratio for the calculation of corner mesh impact force is shown in Fig. 4.

For high contact ratio gear pairs, such as helical gear and herringbone gear, some teeth pairs have already been in the meshing state when the corner mesh impact happens. Based on the general impact dynamics theory, impact energy equation can be given as:

$$
\left\{\begin{array}{c}
E_{k}=\frac{1}{2} \frac{I_{1} I_{2} v_{s}^{2}}{\left(I_{1} r_{b 2}^{\prime 2}+I_{2} r_{b 1}^{2}\right)}=\frac{1}{2 q_{s}} \delta_{s}^{2}+\frac{1}{2 q_{r}} \delta_{r}^{2} \\
\delta_{s}=F_{s} \cdot q_{s}, \quad \delta_{r}=\cos \theta F_{s} \cdot q_{r}
\end{array} ;\right.
$$

where $E_{k}$ is the impact kinetic energy; $I_{1}$ and $I_{2}$ are rotational inertia of pinion and gear; $v_{s}$ is the impact velocity at meshing impact point $D ; r_{b 1}$ is the standard base circle radius of pinion; $r_{b 2}^{\prime}$ is instantaneous base circle radius of gear in corner meshing; $q_{s}$ is the flexibility of corner meshing teeth pair along the relative principal direction, which can be calculated by LTCA; $q_{r}$ is the flexibility of normal meshing teeth pairs except the impact teeth pair; $\delta_{s}$ is impact deformation on the corner mesh teeth; $\delta_{r}$ is impact deformation about the normal mesh teeth; $\Theta$ 


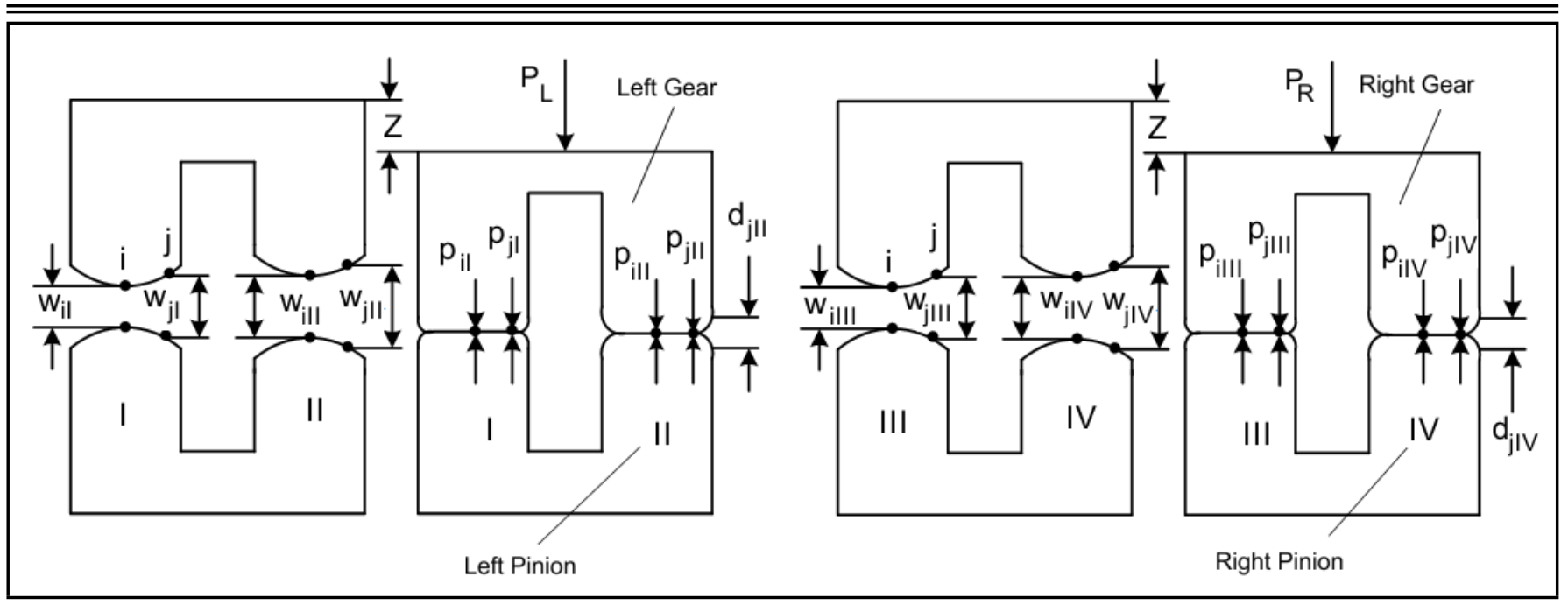

Figure 1. Herringbone gear model for loaded tooth contact analysis.

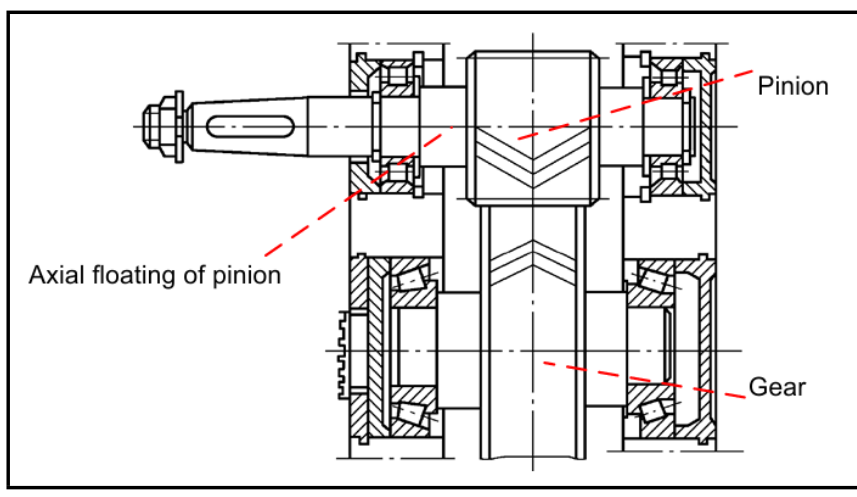

Figure 2. The installation structure diagram of a herringbone gear.

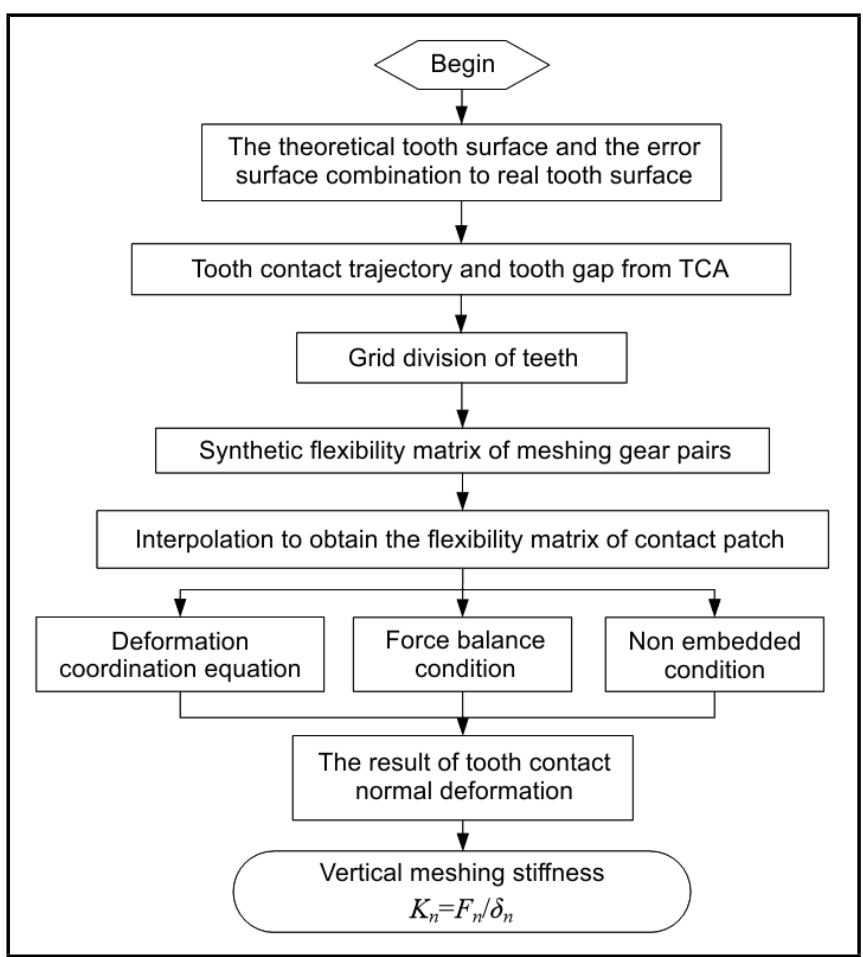

Figure 3. The process of gear mesh stiffness calculation.

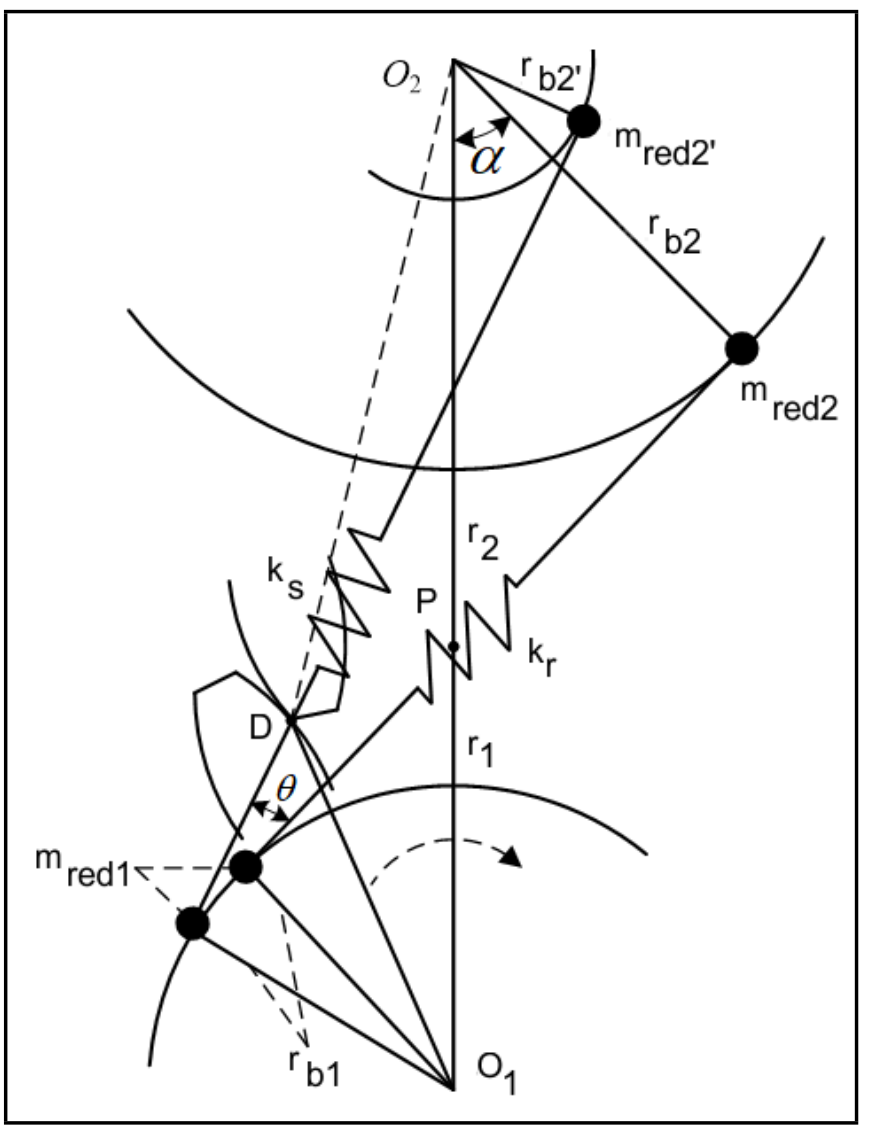

Figure 4. The impact model considering teeth contact ratio.

is the angle between the relative principal direction of corner mesh teeth and normal mesh teeth as shown in Fig. 4.

The corner mesh impact force $F_{s}$ can be obtained from the following equation:

$$
F_{s}=v_{s} \sqrt{\frac{I_{1} I_{2}}{\left(I_{1} r_{b 2}^{\prime 2}+I_{2} r_{b 1}^{2}\right)\left(q_{s}+q_{r} \cos ^{2} \theta\right)}} .
$$

\subsubsection{Equivalent coefficient of meshing friction torque}

Because of the existence of tooth surface roughness, manufacture and installation error, and other factors, herringbone gear teeth almost always work under the mixed EHL condition, 


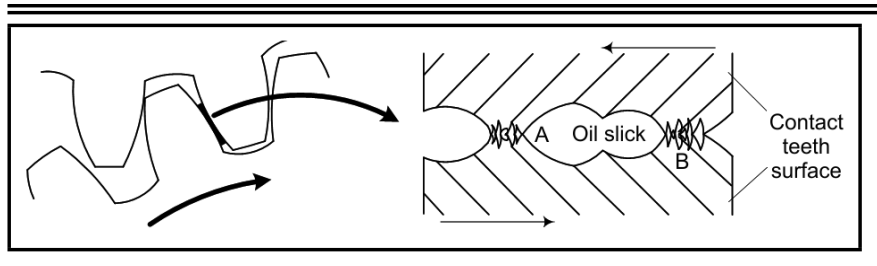

Figure 5. The tooth contact state under mixed EHL.

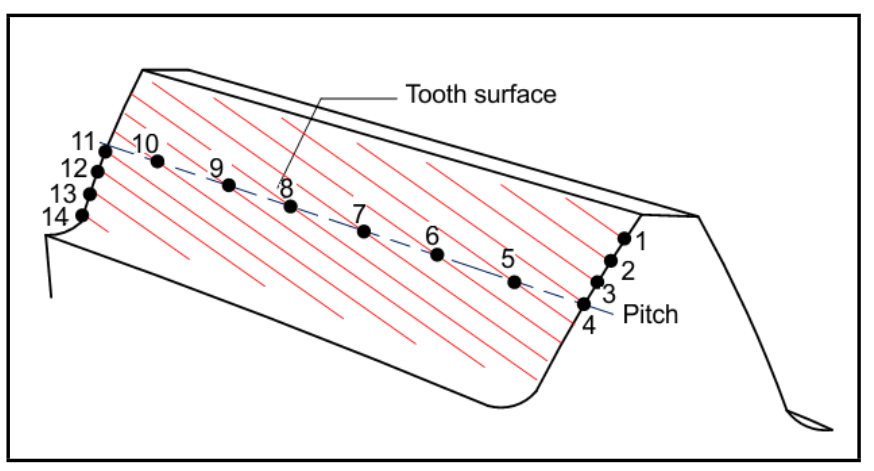

Figure 6. Schematic diagram of tooth contact trajectoryL.

Table 1. Instantaneous contact of gear pair.

\begin{tabular}{|c|c|}
\hline The rotation angle of pinion & Meshing line number \\
\hline \hline 0 & $1,6,11$ \\
$1 / 5 \times \Delta \tau$ & $2,7,12$ \\
$2 / 5 \times \Delta \tau$ & $3,8,13$ \\
$3 / 5 \times \Delta \tau$ & $4,9,14$ \\
$4 / 5 \times \Delta \tau$ & 5,10 \\
$\Delta \tau$ & $1,6,11$ \\
\hline
\end{tabular}

where both EHL oil slick (A point) and boundary lubrication contact peak ( $B$ point) occur between meshing teeth surfaces. It can be seen in Fig. 5 .

Based on the modified Coulomb's law, the magnitude of friction force is proportional to the nominal tooth load, and coefficient of friction is determined by the nominal relative sliding velocity, scrolling speed, and lubricant viscosity coefficient, etc. The comprehensive friction coefficient in the tooth surface contact point under mixed EHL condition can be expressed as Eq. (7).

$$
\mu_{M L}=f_{\alpha} \mu_{E L}+\left(1-f_{\alpha}\right) \mu_{B L}
$$

where $\mu_{L}$ is the coefficient of friction in mixed EHL condition; $\mu_{E L}$ is the friction coefficient of EHL; $\mu_{B L}$ is the friction coefficient under the condition of boundary lubrication; $f_{\alpha}$ is peak contact load distribution percentage among EHL which can be found in $\mathrm{Zhu}$ and $\mathrm{Hu}^{21}$ The dynamic parameters are mainly related to the relative sliding speed, tooth surface load, dynamic viscosity of lubrication oil etc., the detailed calculation principles can be found in reference. ${ }^{21}$

Meshing contact traces of a herringbone gear which are got from LTCA are shown in Fig. 6.

A total of 14 contact lines is given in Fig. 6, every five intervals are one meshing cycle. Table. 1 is the instantaneous contact situation, where $\delta \tau$ is the rotation angle in one meshing cycle.

The equivalent friction torque coefficients of pinion and gear are shown as:

$$
\begin{array}{r}
\chi_{p k}=\sum_{i=1}^{c e i l\left(\frac{n+1-k}{5}\right)} \sum_{j=1}^{\tau_{k+5(i-1)}} \lambda_{k+5(i-1), j} \mu_{k+5(i-1), j} . \\
\cdot X_{k+5(i-1), j} \cdot \operatorname{sgn}\left(r_{k+5(i-1), j}-r_{p}\right) \ldots \ldots \\
(k=1,2,3,4,5) ;
\end{array}
$$

$$
\begin{array}{r}
\chi_{p k}=\sum_{i=1}^{\operatorname{ceil}\left(\frac{n+1-k}{5}\right)} \sum_{j=1}^{\tau_{k+5(i-1)}} \lambda_{k+5(i-1), j} \mu_{k+5(i-1), j} . \\
\cdot X_{k+5(i-1), j} \cdot \operatorname{sgn}\left(r_{k+5(i-1), j}-r_{p}\right) \ldots \ldots \\
(k=1,2,3,4,5) ;
\end{array}
$$

where $n$ is the number of meshing lines from entering to exiting the meshing processes; $k$ is the rotation order number; $\tau_{k+5(i-1)}$ is the number of discrete contact points in the $k+$ $5(i-1)$ meshing line; $\lambda_{k+5(i-1), j}, \mu_{k+5(i-1), j}, X_{k+5(i-1), j}$, $r_{k+5(i-1), j}$ respectively are the load distribution coefficient, coefficient of friction, friction arm, and the distance from the centre of pinion to contact point at $j$ contact point of the $k+5(i-1)$ meshing line; $r_{p}$ is pitch radius of pinion; $r_{p}^{\prime}$, $r_{g}^{\prime}$ are base radii of pinion and gear; ceil is the function for minimum integer larger than a number; sgn is the "sign" or "signum" function, with value +1 for positive values, and -1 for negative values.

\subsection{Dynamic Model of Herringbone Gear}

Considering meshing stiffness excitation, corner mesh impact excitation, and the tooth surface friction excitation, the herringbone gear vibration model is established as Fig. 7. It is a two-parameter (stiffness and damping) model with torsional and lateral vibration, which means that it includes both the linear and rotational equations of the systems motion. This model represents a system with twelve degrees of freedom, which is driven by electric motor torque, and loaded with external torque. In this study, the pinion is supported by cylindrical roller bearings, and the gear is supported by tapered roller bearings. Necessary explanation is that the main purpose of this paper is to study the quality of meshing tooth surface which is mainly under the consideration of internal excitations, so external excitations such as motor torque and other external torques were neglected.

Twelve degrees of displacement freedom can be expressed as

$$
\delta=\left(y_{p 1}, z_{p 1}, \theta_{p 1}, y_{g 1}, z_{g 1}, \theta_{g 1}, y_{p 2}, z_{p 2}, \theta_{p 2}, y_{g 2}, z_{g 2}, \theta_{g 2}\right)^{\mathrm{T}} ;
$$

where $y_{i j}, z_{i j}, \Theta_{i j}(\mathrm{i}=\mathrm{p}, \mathrm{g} ; \mathrm{j}=1,2)$ are the vibration displacements and the vibration angles at the points of $O p_{1}, O p_{2}, O g_{1}$, and $\mathrm{Og}_{2}$

According to the Newton's law, dynamic equations of system can be obtained from Fig. reffig.7.

$$
\left\{\begin{array}{l}
m_{p 1} \ddot{y}_{p 1}+c_{p 1 y} \dot{y}_{p 1}+k_{p 1 y} y_{p 1}=-F_{y 1}+m_{p 1} g \\
m_{p 1} \ddot{z}_{p 1}+c_{p 12 z}\left(\dot{z}_{p 1}-\dot{z}_{p 2}\right)+k_{p 12 z}\left(z_{p 1}-z_{p 2}\right)=-F_{z 1} \\
I_{p 1} \ddot{\theta}_{p 1}=-F_{y 1} \cdot R_{p}+F_{n 1} \cdot \chi_{p 1}+T_{p 1}-F_{s 1} \cdot R_{p}
\end{array} ;\right.
$$




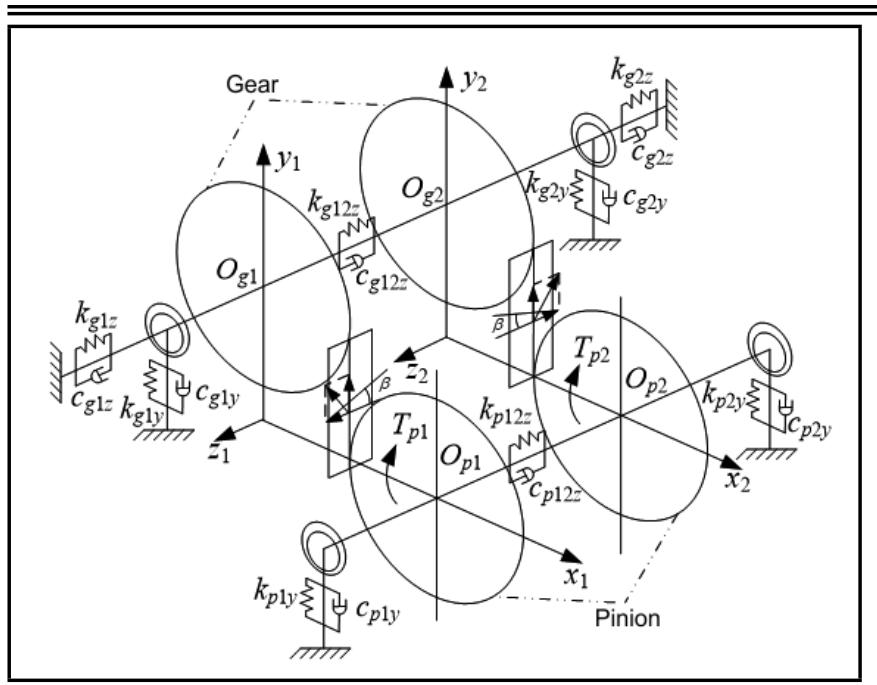

Figure 7. Dynamic model of herringbone gear pairs.

$$
\left\{\begin{array}{r}
m_{g 1} \ddot{y}_{g 1}+c_{g 1 y} \dot{y}_{g 1}+k_{g 1 y} y_{g 1}=F_{y 1}+m_{g 1} g \\
m_{g 1} \ddot{z}_{g 1}+c_{g 1 z} \dot{z}_{g 1}+k_{g 1 z} z_{g 1}+c_{g 12 z}\left(\dot{z}_{g 1}-\dot{z}_{g 2}\right)+ \\
+k_{g 12 z}\left(z_{g 1}-z_{g 2}\right)=F_{z 1} \\
I_{g 1} \ddot{\theta}_{g 1}=F_{y 1} \cdot R_{g}-F_{n 1} \cdot \chi_{g 1}-T_{g 1}+F_{s 1} \cdot R_{g}
\end{array}\right.
$$

$$
\left\{\begin{array}{l}
m_{p 2} \ddot{y}_{p 2}+c_{p 2 y} \dot{y}_{p 2}+k_{p 2 y} y_{p 2}=-F_{y 2}+m_{p 2} g \\
m_{p 2} \ddot{z}_{p 2}-c_{p 12 z}\left(\dot{z}_{p 1}-\dot{z}_{p 2}\right)-k_{p 12 z}\left(z_{p 1}-z_{p 2}\right)=-F_{z 2} \\
I_{p 2} \ddot{\theta}_{p 2}=-F_{y 2} \cdot R_{p}+F_{n 2} \cdot \chi_{p 2}+T_{p 2}-F_{s 2} \cdot R_{p}
\end{array}\right.
$$

$$
\left\{\begin{array}{c}
m_{g 2} \ddot{y}_{g 2}+c_{g 2 y} \dot{y}_{g 2}+k_{g 2 y} y_{g 2}=F_{y 2}+m_{g 2} g \\
m_{g 2} \ddot{z}_{g 2}+c_{g 2 z} \dot{z}_{g 2}+k_{g 2 z} z_{g 2}-c_{g 12 z}\left(\dot{z}_{g 1}-\dot{z}_{g 2}\right)+ \\
-k_{g 12 z}\left(z_{g 1}-z_{g 2}\right)=F_{z 2} \\
I_{g 2} \ddot{\theta}_{g 2}=F_{y 2} \cdot R_{g}-F_{n 2} \cdot \chi_{g 2}-T_{g 2}+F_{s 2} \cdot R_{g}
\end{array} ;\right.
$$

where $m_{p 1}, m_{p 2}, m_{g 1}, m_{g 2}, I_{p 1}, I_{p 2}, I_{g 1}, I_{g 2}$ are the mass and inertia of pinion and gear; $R_{p}, R_{g}$ are the pitch radii of pinion and gear; $c_{p 1 y}, c_{p 2 y}, c_{g 1 y}, c_{g 2 y}, c_{g 1 z}, c_{g 2 z}, k_{p 1 y}, k_{p 2 y}$, $k_{g 1 y}, k_{g 2 y}, k_{g 1 z}, k_{g 2 z}$ are the equivalent support damping and stiffness which consider rolling element bearings at the points of $O_{p 1}, O_{p 2}, O_{g 1}, O_{g 2} ; c_{p 12 z}, c_{g 12 z}, k_{p 12 z}, k_{g 12 z}$ are axial equivalent damping and stiffness of undercuts; $F_{n 1}, F_{n 2}$ are dynamic meshing forces about right and left helical teeth; $F_{y 1}$, $F_{y 2}, F_{z 1}, F_{z 2}$ are dynamic meshing forces along the meshing line direction and axial direction; $p 1, p 2, g 1, g 2$ are friction torque coefficients of pinion and gear; $F_{s 1}, F_{s 2}$ are corner meshing impact forces about right and left meshing teeth.

The radial dynamic load $F_{i j}(t)$ and axial dynamic load $F_{a}(t)$ in points of $O_{p 1}, O_{p 2}, O_{g 1}, O_{g 2}$ can be obtained as:

$$
\left\{\begin{array}{l}
F_{i j}(t)=k_{i j y} y_{i j} \cdots \quad(i=p, g ; j=1,2) \\
F_{a}(t)=k_{g 1 z} z_{g 1}+k_{g 2 z} z_{g 2}
\end{array} .\right.
$$

\subsection{Calculation and Analysis of Meshing Vi- bration}

The dynamic parameters of single stage herringbone gear transmission system are listed in Table. 2.
Table 2. Single stage herringbone gear parameters.

\begin{tabular}{||l|c|c||}
\hline Parameters & Pinion & Gear \\
\hline \hline Normal module [mm] & 6 & 6 \\
Pressure angle [ ${ }^{\circ}$ ] & 20 & 20 \\
Spiral angle [ ${ }^{\circ}$ ] & 24.43 & -24.43 \\
Rating torque [N.m] & - & 828 \\
Density [g/cm3] & 7.85 & 7.85 \\
Teeth & 17 & 44 \\
Tooth width [mm] & 55 & 55 \\
Drive wheel speed [r/min] & 2000 & - \\
\hline
\end{tabular}

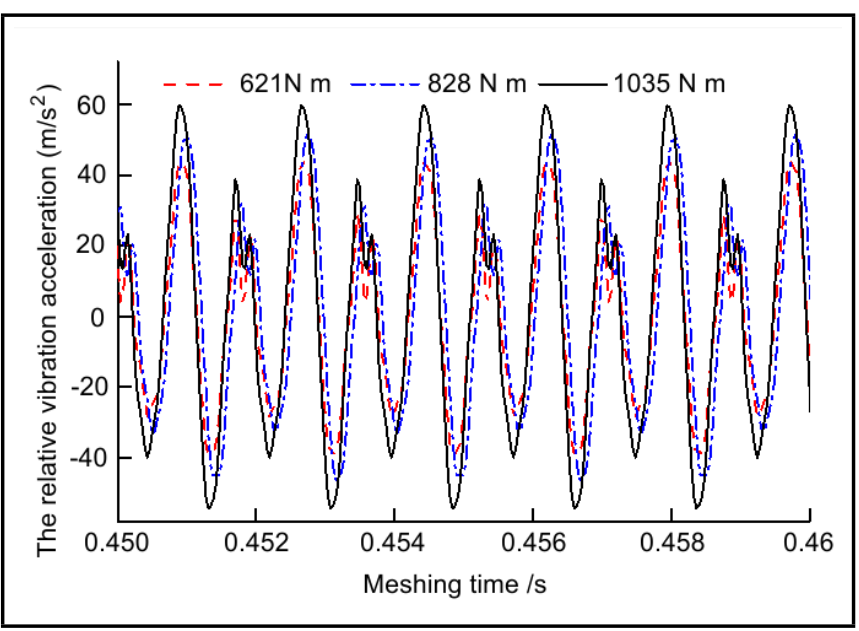

Figure 8. Time diagram of the relative vibration acceleration.

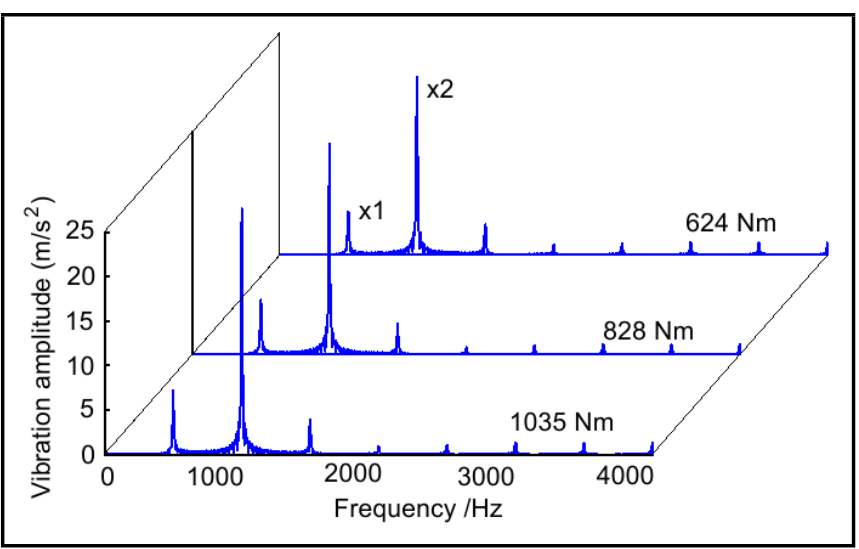

Figure 9. Frequency diagram of the relative vibration acceleration.

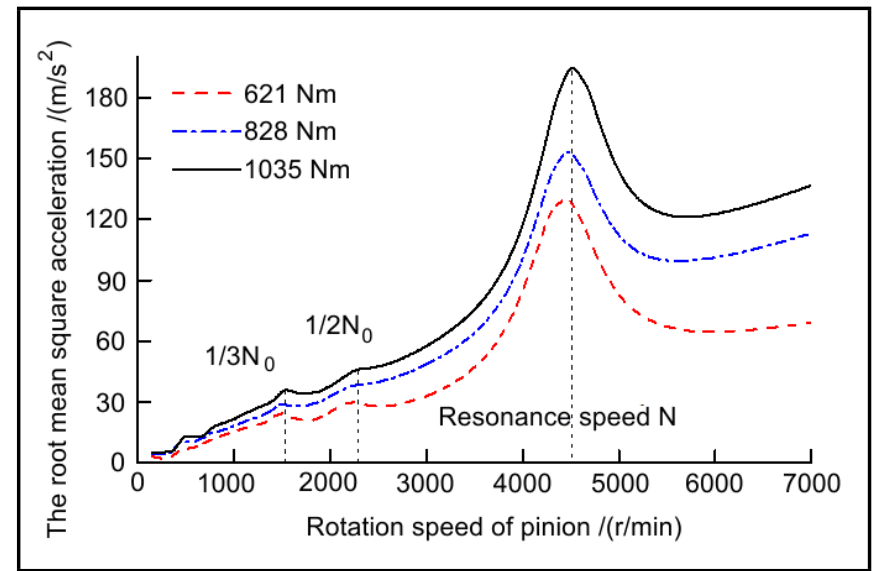

Figure 10. Rotation speed diagram of the relative vibration acceleration. 


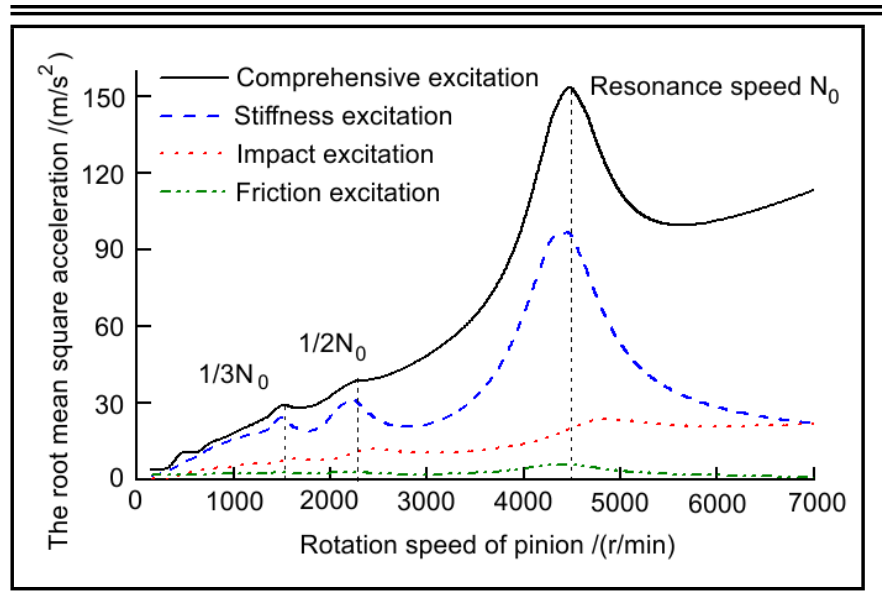

Figure 11. Vibration response under different excitation.

The relative vibration acceleration along the meshing line direction is shown in Fig. 8-Fig. 10.

Vibration acceleration of meshing line direction increases with increasing load which can be concluded from Fig. 8. The root mean square (RMS) values are $25.10 \mathrm{~m} / \mathrm{s}^{2}, 29.38 \mathrm{~m} / \mathrm{s}^{2}$, and $34.23 \mathrm{~m} / \mathrm{s}^{2}$ under corresponding three external torques of $621 \mathrm{~N} \cdot \mathrm{m}, 828 \mathrm{~N} \cdot \mathrm{m}$, and $1035 \mathrm{~N} \cdot \mathrm{m}$. The maximum amplitudes of frequency-domain respectively are $19.94 \mathrm{~m} / \mathrm{s}^{2}$, $23.71 \mathrm{~m} / \mathrm{s}^{2}$, and $27.68 \mathrm{~m} / \mathrm{s}^{2}$ in Fig. 9, which are at twice the tooth meshing frequency because they are closer to the resonance frequency of $1292 \mathrm{~Hz}$. The RMS values of acceleration peaks in Fig. 10 respectively are corresponding to the $1 / 3,1 / 2$ and 1 resonant frequency. And the maximum acceleration values under the resonance frequency respectively are $125.92 \mathrm{~m} / \mathrm{s}^{2}, 151.01 \mathrm{~m} / \mathrm{s}^{2}$, and $194.05 \mathrm{~m} / \mathrm{s}^{2}$. Worthy of attention is that the RMS values of acceleration away from the resonance peaks continue to rise with the increase in rotational speed, which is caused by the corner meshing impact force. This result is consistent with the conclusion in gear manual ${ }^{22}$ that dynamic load coefficient increased with the work speeds increasing.

To analyse the vibration effects of each excitation factor, RMS values of acceleration under different excitations are presented in Fig. 11, and "comprehensive excitation" means the vibration response considering the three excitations simultaneously. It should be noted that "comprehensive excitation" are not the linear superposition of "three excitations", so it is bigger than the sum of the individual responses.

It is shown that time-varying meshing stiffness excitation accounts for the major part of vibration response; in contrast, corner mesh impact excitation accounts for a smaller percentage, and teeth friction occupied the smallest proportion. This conclusion will be helpful in further investigations such as the tooth surface optimum design of vibration and noise reduction.

\section{VIBRATION LOADS TRANSMISSION OF HERRINGBONE GEAR}

Dynamic loads at the equivalent supporting positions of herringbone gear system are calculated in the previous chapter, the following work is to analyse the vibration transmission processes from meshing gear pairs to rolling element bearings, and the internal walls of gearbox bearing holes.

Lubrication of bearings changes the contact stiffness, damping and other parameters. The following bearing lubrication

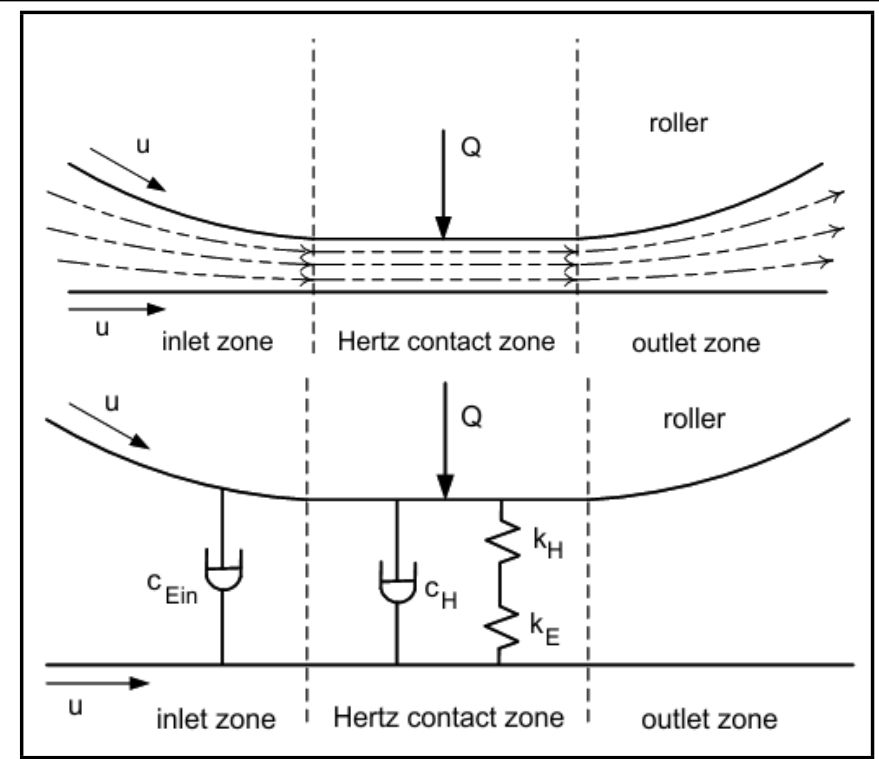

Figure 12. EHL contact model of roller-raceway.

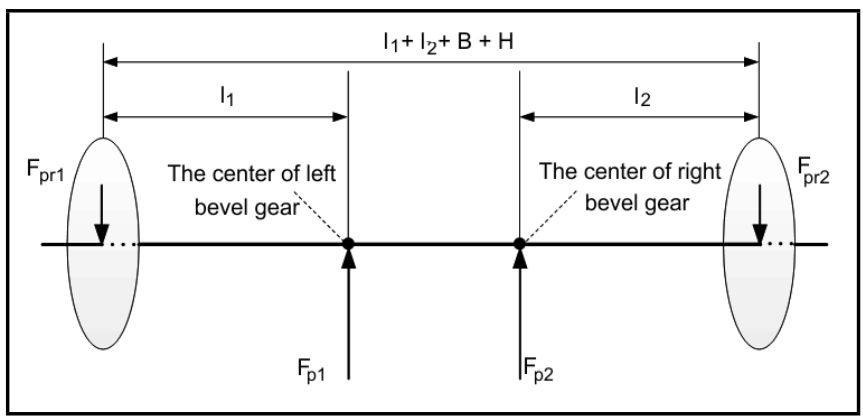

Figure 13. Dynamic load distribution schematic of pinion.

model is established under the consideration of lubricants inlet zone, Hertz contact zone and lubricants outlet zone.

According to Fig. 12, contact stiffness and damping of single roller in EHL state can be expressed as:

$$
\left\{\begin{array}{l}
k_{r b}=\frac{k_{H} k_{E}}{k_{H}+k_{E}} \\
c_{r b}=c_{E i n}+c_{H}
\end{array} ;\right.
$$

where $k_{H}, k_{E}$ are the structural contact stiffness and film contact stiffness at Hertz contact zone; $c_{H}$ is the structural contact damping at Hertz contact zone; $c_{E i n}$ is the contact damping at lubricants inlet zone.

\subsection{Dynamic load distribution and transfer of pinio}

Because the pinion adopts floating installation and the cylindrical roller bearing cannot support axial force, the load distribution of the pinion is similar to that of a spur gear transmission system. To distribute each instantaneous load, the proposed schematic is shown in Fig. 13.

Pinion dynamic loads of left and right supporting cylindrical roller bearings can be got from the following equations.

$$
\left\{\begin{array}{l}
F_{p r 1}(t)=\frac{\left(l_{2}+H+B\right) F_{p 1}(t)+l_{2} F_{p 2}(t)}{l_{1}+l_{2}+H+B} \\
F_{p r 2}(t)=\frac{l_{1} F_{p 1}(t)+\left(l_{1}+H+B\right) F_{p 2}(t)}{l_{1}+l_{2}+H+B}
\end{array} ;\right.
$$

where $l_{1}$ is the distance from left helical gear centre to the left supporting bearing centre; $l_{2}$ is the distance from right heli- 


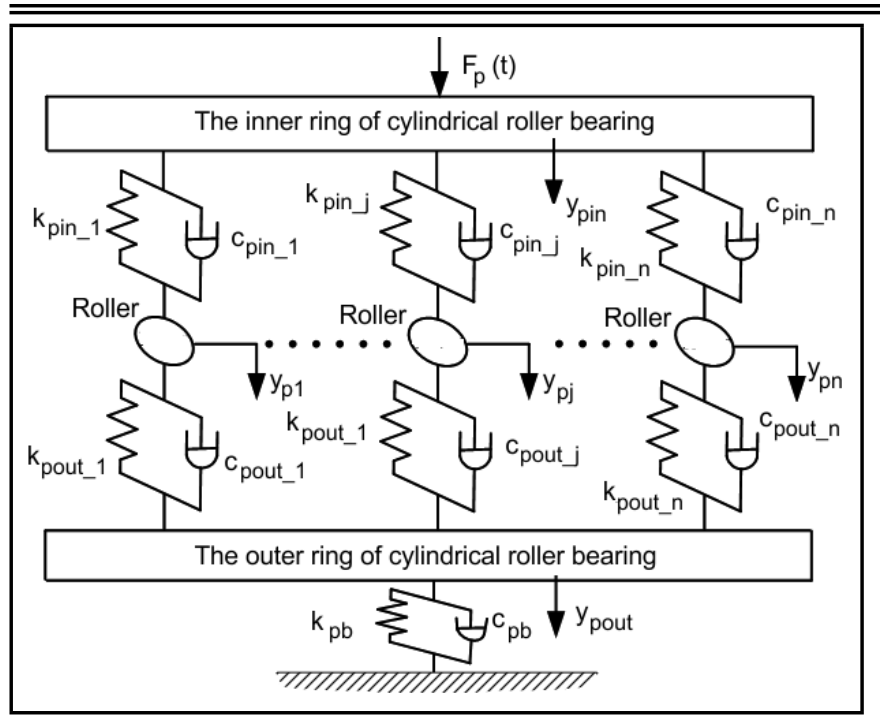

Figure 14. Dynamic model of cylindrical roller bearing.

cal gear centre to the right supporting bearing centre; $B$ is the width of single helical gear; $\mathrm{H}$ is the width of undercut.

The kinetic model of cylindrical roller bearing with $2+j p$ degrees of freedom is established in Fig. 14. where $j_{p}$ is the amount of load bearing rollers.

Displacement freedom degrees of cylindrical roller bearing can be expressed as:

$$
\delta_{p}=\left(y_{\text {pin }}, y_{p 1}, \cdots, y_{p n}, y_{\text {pout }}\right)^{\mathrm{T}}
$$

where $y_{p i n}$ is the vibration displacement of inner ring; $y_{p 1} y_{p n}$ are the vibration displacements of rollers; $y_{\text {pout }}$ is the vibration displacement of outer ring. Eq. (19)-(21) are the dynamic equations of cylindrical roller bearing vibration model.

$$
\left\{\begin{array}{c}
m_{\text {pin }} \ddot{y}_{\text {pin }}+\sum_{j=1}^{n} F_{\text {pin_j }} \cos \psi_{j}=F_{p}(t)+m_{\text {pin }} g \\
m_{p j} \ddot{y}_{p j}-F_{\text {pin-j }}-F_{\text {pout } \_j}=m_{p j} g \cos \psi_{j} \\
m_{\text {pout }} \ddot{y}_{\text {pout }}+\sum_{j=1}^{n} F_{\text {pout } j} \cos \psi_{j}+c_{p b} \dot{y}_{\text {pout }}+ \\
+k_{p b} y_{\text {pout }}=m_{\text {pout }} g
\end{array}\right.
$$

$$
\begin{aligned}
F_{p i n_{-} j}=c_{p i n_{-j} j}\left(\dot{y}_{p i n} \cos \psi_{j}-\dot{y}_{p j}\right)+ & \\
& +k_{p i n_{-} j}\left(y_{p i n} \cos \psi_{j}-y_{p j}\right)
\end{aligned}
$$

$$
\begin{aligned}
F_{\text {pout } \_j}=c_{\text {pout } \_j}\left(\dot{y}_{\text {pout }}\right. & \left.\cos \psi_{j}-\dot{y}_{p j}\right)+ \\
& +k_{\text {pout } \_j}\left(y_{\text {pout }} \cos \psi_{j}-y_{p j}\right)
\end{aligned}
$$

where $F_{p}(t)$ is the dynamic load on the inner ring of cylindrical roller bearing; $m_{\text {pin }}, m_{p j}, m_{\text {pout }}$ respectively are the masses of inner ring, single roller and outer ring about cylindrical roller bearing; $\psi_{j}$ is the load distribution angle; $c_{p i n_{j}}$, $c_{\text {pout }_{j}}, k_{\text {pin }_{j}}, k_{\text {pout }_{j}}$ are the contact damping and contact stiffness between the bearing race and rollers; $c_{p b}, k_{p b}$ are the supporting damping and supporting stiffness which consider the gearbox body.

The radial dynamic load $F_{p}^{\prime}(t)$ of the gearbox bearing hole is obtained as:

$$
F_{p}^{\prime}(t)=k_{p b} y_{\text {pout }} .
$$

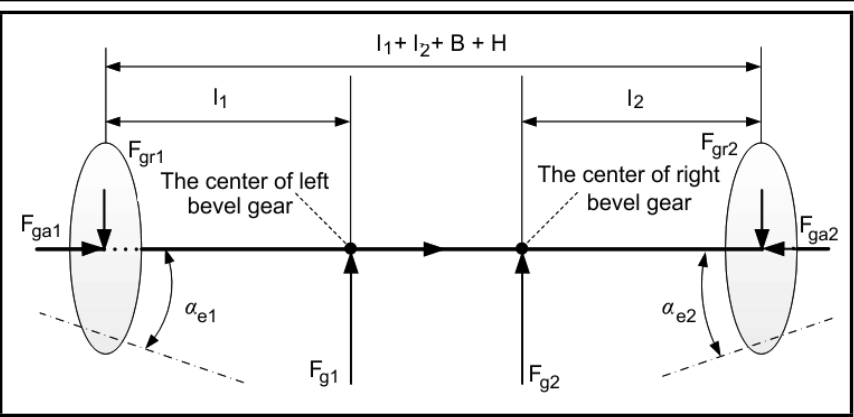

Figure 15. Dynamic load distribution schematic of gear.

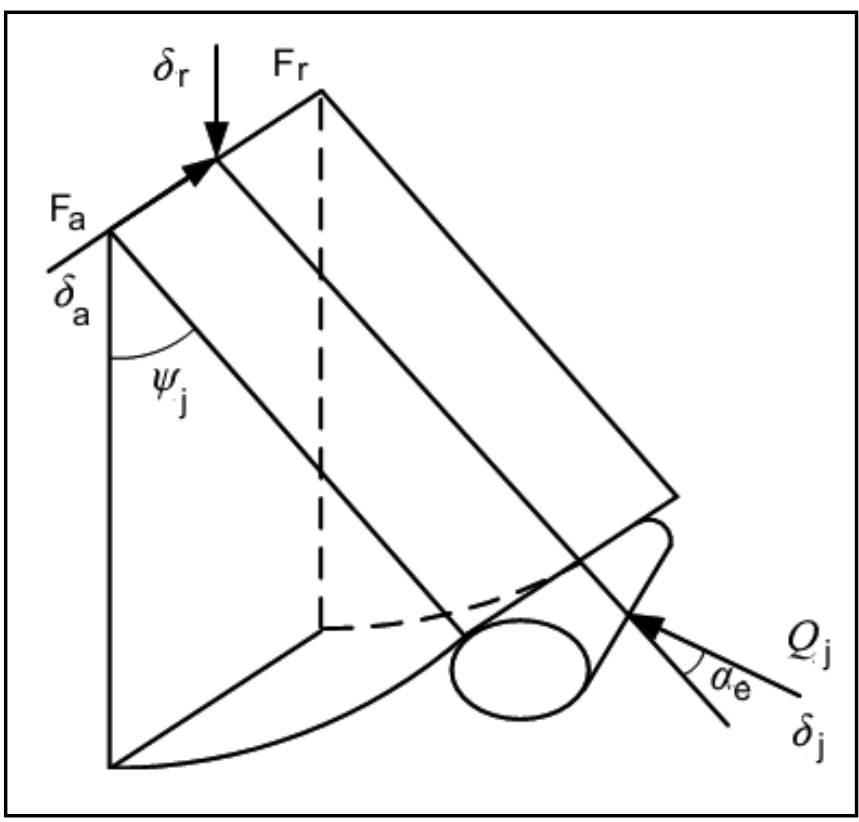

Figure 16. Schematic diagram of tapered roller load distribution.

\subsection{Dynamic Load Distribution and Transfer of Gear}

The load distribution of the gears is similar to that of a helical gear transmission system as the tapered roller bearing can support both radial and axial forces. Each instantaneous load is distributed to both sides bearings according to the schematic about Fig. 15. where $\alpha_{e 1}, \alpha_{e 2}$ are the outer race contact angles of left and right tapered roller bearings.

According to Fig. 16, the force balance conditions in radial and axial direction are given in Eq. (23).

$$
\left\{\begin{array}{c}
\sum_{p=1}^{j_{1}} Q_{1 p} \cos \psi_{1 p} \cos \alpha_{e 1}+\sum_{q=1}^{j_{2}} Q_{2 q} \cos \psi_{2 q} \cos \alpha_{e 2}= \\
=F_{g 1}+F_{g 2} \\
\sum_{q=1}^{j_{2}} Q_{2 q} \sin \alpha_{e 2}-\sum_{p=1}^{j_{1}} Q_{1 p} \sin \alpha_{e 1}=F_{a}
\end{array}\right.
$$

where $j_{1}, j_{2}$ respectively are the amount of load bearing rollers belonging to the left and right tapered roller bearings; $\psi_{1 p}, \psi_{2 q}$ $\left(p=1, \ldots, j_{1}, q=1, \ldots, j_{2}\right)$ respectively are the load distribution angles of left and right tapered roller bearings. The radial and axial loads of outer ring finally are got by the iterative algorithm, and the detailed flow chart of calculating process is shown in Fig. 17.

To study the dynamic load transfer processing of tapered rolling element bearings, the tapered rolling element bearings 


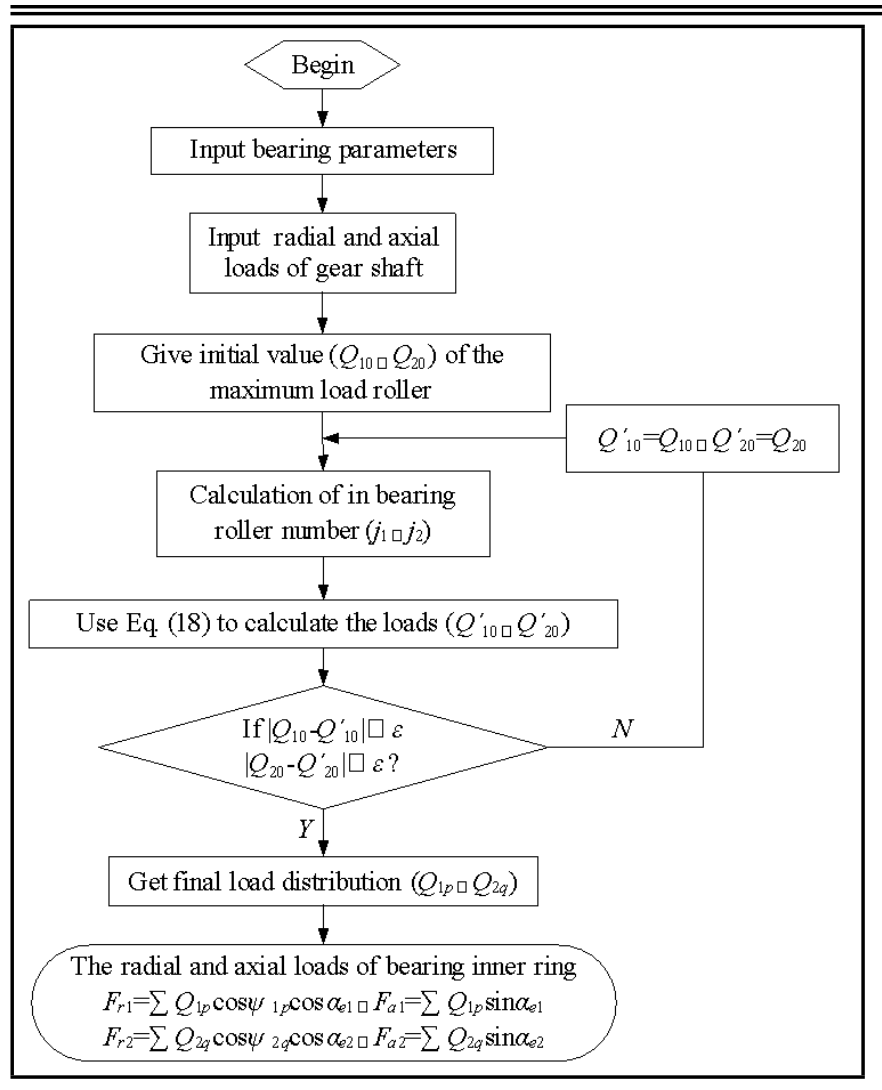

Figure 17. Load distribution calculate processing of tapered rolling element bearings.

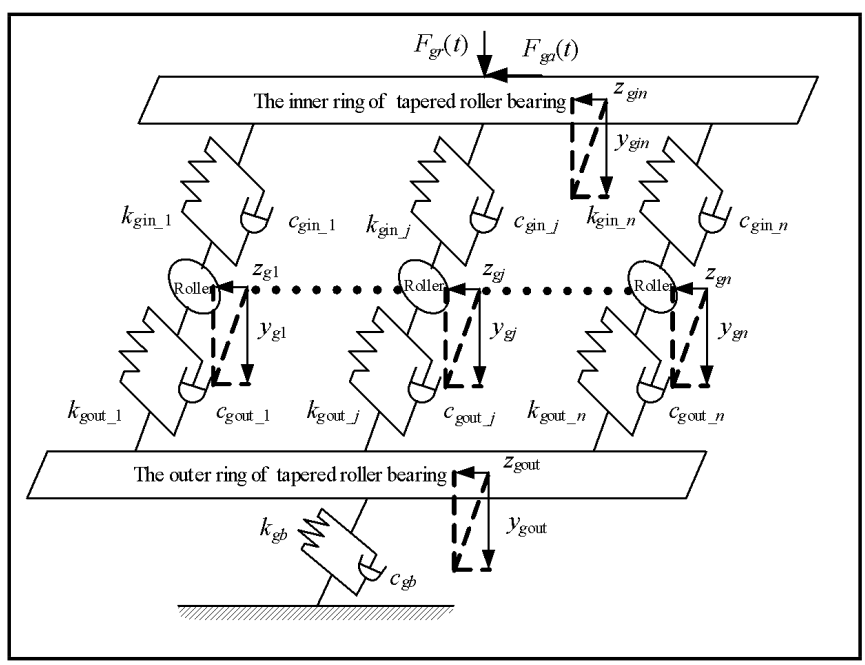

Figure 18. Dynamic model of tapered roller bearing.

kinetic model of $4+2 j_{g}$ freedom degrees is established in Fig. 18. where $j_{g}$ is the amount of tapered rollers which is under load.

Displacement freedom degrees of tapered roller bearing can be expressed as:

$$
\delta_{g}=\left(y_{g i n}, z_{g i n}, y_{g 1}, z_{g 1}, \cdots, y_{g n}, z_{g n}, y_{\text {gout }}, z_{\text {gout }}\right)^{\mathrm{T}}
$$

where $y_{\text {gin }}$ is the radial vibration displacement of inner ring; $y_{g 1} \ldots y_{g n}$ are the radial vibration displacements of rollers; $y_{\text {gout }}$ is the radial vibration displacement of outer ring; $z_{\text {gin }}$ is the axial vibration displacement of inner ring; $z_{g 1} \ldots z_{g n}$ are the axial vibration displacements of rollers; $z_{\text {gout }}$ is the axial vibration displacement of outer ring.
Eq. (25)-(29) are the dynamic equations of tapered roller bearing dynamic model according to the Fig. 18.

$$
\left\{\begin{array}{c}
m_{\text {gin }} \ddot{y}_{\text {gin }}+\sum_{j=1}^{n} F_{\text {gin } \_j} \cos \psi_{j} \cos \alpha_{e}=F_{\text {gr }}(t)+m_{\text {gin }} g \\
m_{\text {gj }} \ddot{y}_{\text {gj }}-\left(F_{\text {gin } j}+F_{\text {gout }} j\right) \cos \alpha_{e}=m_{\text {gj }} g \cos \psi_{j} \\
m_{\text {gout }} \ddot{y}_{\text {gout }}+\sum_{j=1}^{n} F_{\text {gout } j} \cos \psi_{j} \cos \alpha_{e}+ \\
+F_{\text {gout }} \cos \alpha_{e}=m_{\text {gout }} g
\end{array}\right.
$$

$$
\left\{\begin{array}{l}
m_{\text {gin }} \ddot{z}_{\text {gin }}+\sum_{j=1}^{n} F_{\text {gin }-j} \sin \alpha_{e}=F_{\text {ga }}(t) \\
m_{\text {gj }} \ddot{z}_{\text {gj }}-\left(F_{\text {gin } j}+F_{\text {gout } \_j}\right) \sin \alpha_{e}=0 \\
m_{\text {gout }} \ddot{z}_{\text {gout }}+\sum_{j=1}^{n} F_{\text {gout } j} \sin \alpha_{e}+F_{\text {gout }} \sin \alpha_{e}=0
\end{array}\right.
$$

$$
\begin{aligned}
& \quad F_{g i n_{-j} j}= \\
& c_{g i n_{-} j}\left[\left(\dot{y}_{g i n} \cos \psi_{j}-\dot{y}_{g j}\right) \cos \alpha_{e}+\left(\dot{z}_{g i n}-\dot{z}_{g j}\right) \sin \alpha_{e}\right]+ \\
& +k_{g i n_{-} j}\left[\left(y_{g i n} \cos \psi_{j}-y_{g j}\right) \cos \alpha_{e}+\left(z_{g i n}-z_{g j}\right) \sin \alpha_{e}\right] ;
\end{aligned}
$$

$$
\begin{aligned}
& \quad F_{\text {gout_j }}= \\
& c_{\text {gout_j } j}\left[\left(\dot{y}_{\text {gout }} \cos \psi_{j}-\dot{y}_{g j}\right) \cos \alpha_{e}+\left(\dot{z}_{\text {gout }}-\dot{z}_{g j}\right) \sin \alpha_{e}\right]+ \\
& +k_{\text {gout_ } j}\left[\left(y_{\text {gout }} \cos \psi_{j}-y_{g j}\right) \cos \alpha_{e}+\left(z_{\text {gout }}-z_{g j}\right) \sin \alpha_{e}\right] ;
\end{aligned}
$$

$$
\begin{aligned}
& F_{\text {gout }}=c_{\text {gb }}\left(\dot{y}_{\text {gout }} \cos \alpha_{e}+\dot{z}_{\text {gout }} \sin \alpha_{e}\right)+ \\
& +k_{\text {gb }}\left(y_{\text {gout }} \cos \alpha_{e}+z_{\text {gout }} \sin \alpha_{e}\right)
\end{aligned}
$$

where $F_{g r}(t)$ is the dynamic load on the inner ring of tapered roller bearing toward radial direction; $F_{g a}(t)$ is the dynamic load on the inner ring of tapered roller bearing toward axial direction; $m_{p i n}, m_{p j}, m_{\text {pout }}$ respectively are the masses of inner ring, single roller and outer ring about tapered roller bearing; $\alpha_{e}$ is the contact angle of tapered roller bearing; $c_{g i n_{j}}$, $c_{\text {gout }_{j}}, k_{\text {gin }_{j}}, k_{\text {gout }_{j}}$ are the normal contact damping and contact stiffness between the bearing race and rollers; $c_{g b}, k_{g b}$ are the normal supporting damping and supporting stiffness which consider the gearbox body.

The radial dynamic load $F_{g r}(t)$ and axial dynamic load $F_{g a}(t)$ of the gearbox bearing hole are obtained as:

$$
\left\{\begin{array}{l}
F^{\prime}{ }_{g r}(t)=\cos \alpha_{e} k_{\text {gb }}\left(y_{\text {gout }} \cos \alpha_{e}+z_{\text {gout }} \sin \alpha_{e}\right) \\
F_{\text {ga }}^{\prime}(t)=\sin \alpha_{e} k_{\text {gb }}\left(y_{\text {gout }} \cos \alpha_{e}+z_{\text {gout }} \sin \alpha_{e}\right)
\end{array} ;\right.
$$

\subsection{Example of Dynamic Load Distribution and Transfer}

The basic parameters of rolling element bearings in herringbone gear transmission system are shown in Table. 3 .

The inner and outer loads of every bearings are calculated by the above theory, Fig. 19-Fig. 20 are dynamic loads of cylindrical roller bearings, and Fig. 21-Fig. 24 are dynamic loads of tapered roller bearings. 
Table 3. The basic parameters of roll bearing.

\begin{tabular}{||c|c|c|c|c|}
\hline \multirow{2}{*}{ Parameters } & \multicolumn{2}{|c|}{ Cylindrical roller bearing } & \multicolumn{2}{c|}{ Tapered roller bearing } \\
\cline { 2 - 5 } & Left & Right & Left & Right \\
\hline \hline Diameter of inner ring [mm] & 55 & 55 & 70 & 70 \\
Diameter of outer ring [mm] & 100 & 100 & 100 & 100 \\
Bearing width [mm] & 21 & 21 & 20 & 20 \\
Number of roller & 24 & 24 & 28 & 28 \\
Length of roller [mm] & 15 & 15 & 18 & 18 \\
Equivalent diameter of roller [mm] & 8 & 8 & 6 & 6 \\
Contact angle [ $\left.{ }^{\circ}\right]$ & - & - & $11^{\circ} 53^{\prime}$ & $11^{\circ} 53^{\prime}$ \\
\hline
\end{tabular}

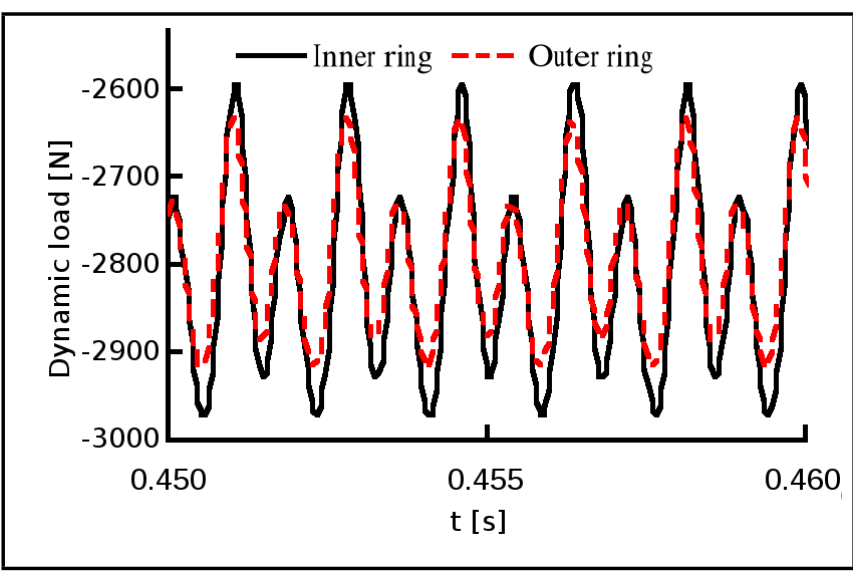

Figure 19. Radial dynamic loads of left cylindrical roller bearing.

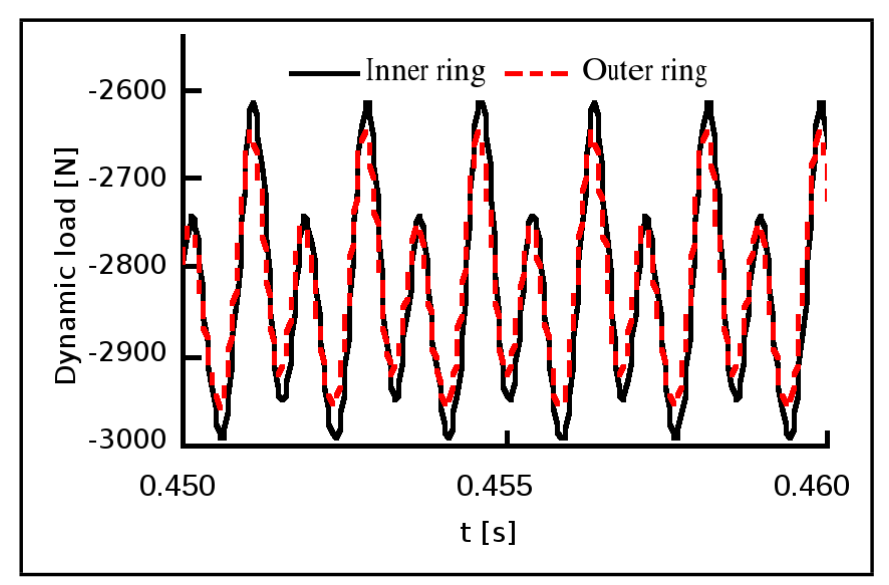

Figure 20. Radial dynamic loads of right cylindrical roller bearing.

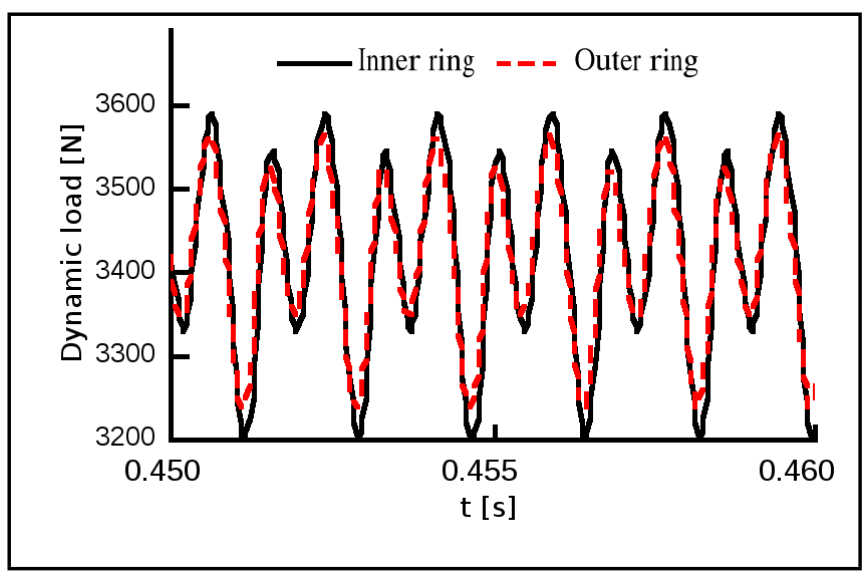

Figure 21. Radial dynamic loads of left tapered roller bearing.

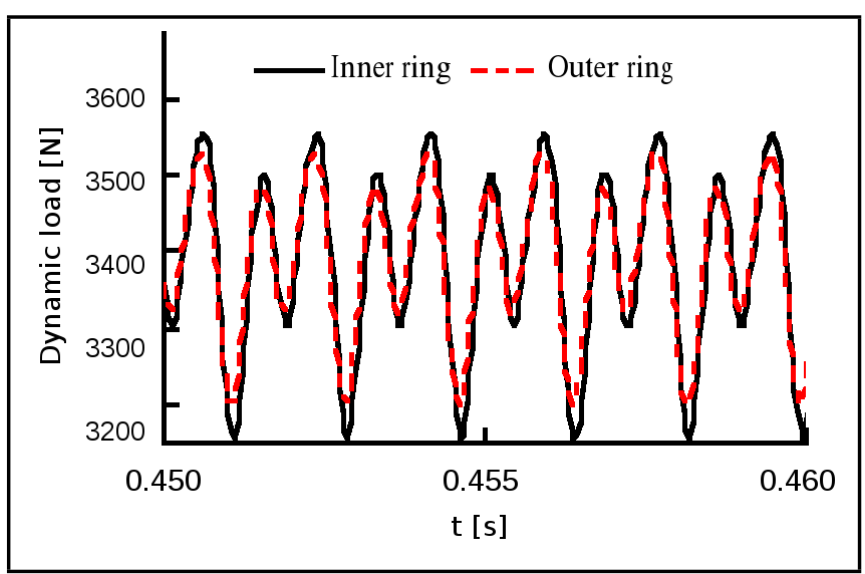

Figure 22. Radial dynamic loads of right tapered roller bearing.

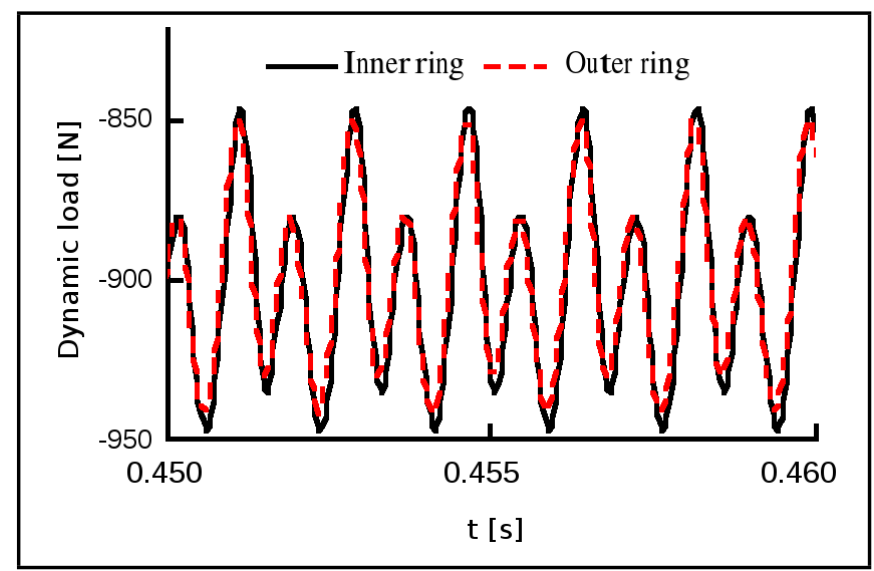

Figure 23. Axial dynamic loads of left tapered roller bearing.

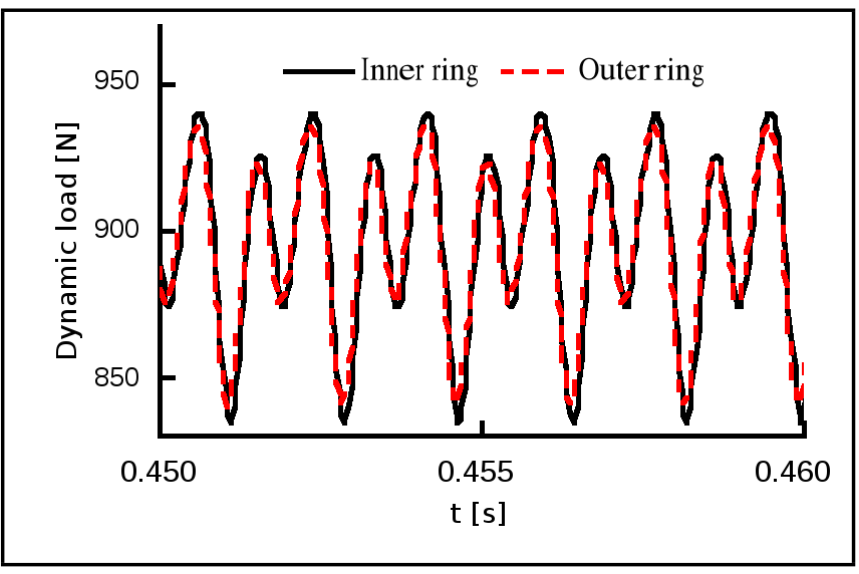

Figure 24. Axial dynamic loads of right tapered roller bearing. 
It can be seen from Fig. 19-Fig. 24 that the dynamic coefficients of outer rings are lower than the inner rings. That is because time-varying contact stiffness of bearing is neglected in this paper, so the cylindrical or tapered roller bearings played a role in the vibration and noise reduction of herringbone gear transmission system. And when we choose rolling element bearings type for herringbone gear system, not only to consider the load, speed and other operating conditions, but also should consider the aspects of vibration isolation and noise reduction

\section{FLUID-SOLID COUPLING HERRINGBONE GEAR BOX VIBRATION ANALYSIS}

\subsection{Fluid-Solid Coupling Gearbox Model}

For the FE analysis of the gearbox, existing literatures ${ }^{23-28}$ generally only consider the influence of lubrication oil concerning lubrication and cooling. Actually, lubrication oil itself will affect the natural modal, dynamic response, and other dynamic characteristics of the whole gearbox system. The fluidsolid coupling effect between the gearbox inner wall and lubrication oil is investigated in this paper.

Fluid load is produced in the fluid-solid coupling surface between the gearbox body and lubrication oil when structure vibration occurs. So, fluid wave equation and box dynamic equation must be calculated at the same time.

The fluid is assumed as inviscid, compressible and microvariations, and kinetic equations of fluid elements with Galerkin method are shown as:

$$
\left[M_{f}\right]\{\ddot{p}\}+\rho[R]\{\ddot{u}\}+\left[K_{f}\right]\{p\}=0 ;
$$

where:

$$
\left\{\begin{array}{l}
{\left[M_{f}\right]=\frac{1}{c^{2}}} \\
{\left[K_{f}\right]=} \\
{[R]=\rho}
\end{array} .\right.
$$

Here, $\left[M_{f}\right]$ is mass matrix of lubricant; $\left[K_{f}\right]$ is stiffness matrix of lubricant; $[R]$ is the coupling matrix of fluid-solid contact surface; $\rho$ is the density of lubricant; $\{p\},\{u\}$ respectively are the pressure and displacement vectors of grid nodes; $\{c\}$ is the acoustic velocity in fluid medium; $\left\{N_{p}\right\},\left\{N_{u}\right\}$ respectively are the shape functions of pressure and displacement; $\left\{B_{p}\right\}$ is the gradient derivative of fluid pressure; $\{n\}$ is the normal vector of the boundary surface.

Since the gearbox is under the effects of external load excitation and fluid excitation simultaneously, according to the principle of Hamilton, a unified matrix of fluid-solid coupling equation is obtained as:

$$
\begin{gathered}
\left(\begin{array}{cc}
{\left[M_{g}\right]} & 0 \\
\rho[R] & {\left[M_{f}\right]}
\end{array}\right)\left(\begin{array}{c}
\{\ddot{u}\} \\
\{\ddot{p}\}
\end{array}\right)+\left(\begin{array}{cc}
{\left[C_{g}\right]} & 0 \\
0 & {\left[C_{f}\right]}
\end{array}\right)\left(\begin{array}{c}
\{\dot{u}\} \\
\{\dot{p}\}
\end{array}\right)+ \\
\left(\begin{array}{cc}
{\left[K_{g}\right]} & {[R]} \\
0 & {\left[K_{f}\right]}
\end{array}\right)\left(\begin{array}{c}
\{u\} \\
\{p\}
\end{array}\right)=\left(\begin{array}{c}
\left\{F_{g}\right\} \\
0
\end{array}\right)
\end{gathered}
$$

where $\left[M_{g}\right]$ is the mass matrix of gearbox; $\left[K_{g}\right]$ is the stiffness matrix of gearbox; $\left[C_{g}\right]$ is the damping matrix of gearbox; $\left[F_{g}\right]$ is external load excitation.

Table. 4 gives the parameters of gearbox, and Fig. 25 is the corresponding 3-D model. where $R_{p 1}-R_{p 6}$ are the concerned positions where the vibration acceleration values will be calculated.

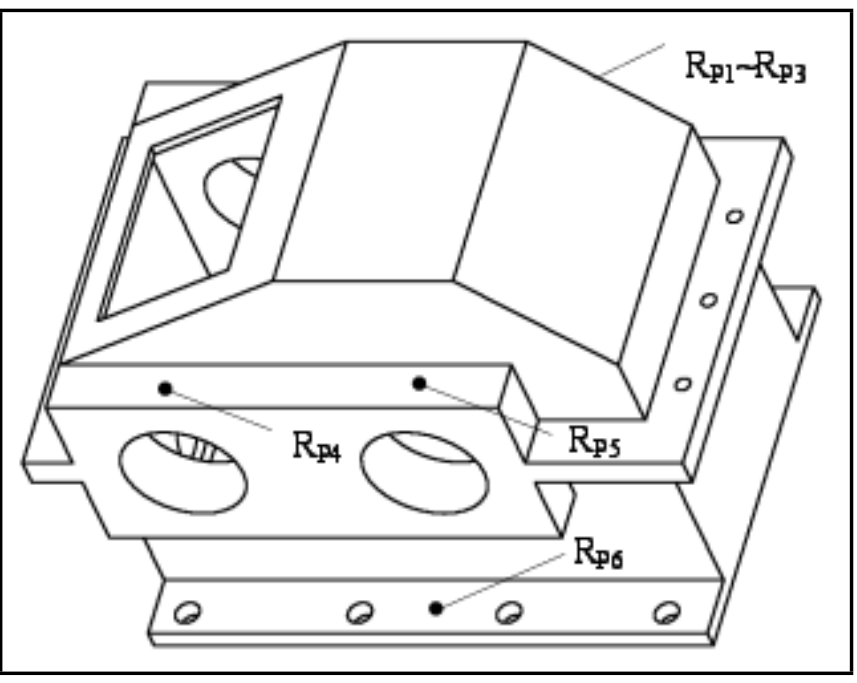

Figure 25. 3-D model of herringbone gearbox.

Meshing the gearbox body with SOLID45 finite elements using ANSYS software, the number of gearbox elements is 78378 , the number of gearbox nodes is 21599 . And meshing the lubrication oil with a FLUID30 fluid unit grid, the total number of elements is 9770 , and the number of nodes is 2506 . The fluid-solid contact surface of gearbox and lubricant is coupled through the FSI module of ANSYS. ${ }^{24,29}$ All freedom degrees of bolts in gearbox feet are fixed according to the actual installation condition of herringbone gear system.

\subsection{Harmonic Analysis Under Real Loads}

Harmonic response analysis method is commonly used to calculate the steady-state response under sinusoidal wave excitation. And harmonic response characteristics under excitations of various frequencies could help designer to evaluate the kinetic performance of the whole system. The harmonic response method of ANSYS can calculate the response under several different phase harmonic excitations which is applied at the same time and cannot solve the model which is simultaneously applied with various frequencies excitations. ${ }^{25,26}$

To get the harmonic response characteristics of the concerned positions under the real loads, dynamic loads of bearing holes in section 3 are expanded into the Fourier series, thus, harmonic responses of various frequencies can be calculated respectively.

Time varying loads are expanded to the Fourier function in Eq. (34). All the corresponding amplitudes and phase angles of dynamic loads are shown in Table. 5. There is only radial dynamic load of left cylindrical roller bearing to be listed out because of the limitation of length.

$$
P=P_{0}+\sum_{n=1}^{3} A_{n} \cos \left(n \omega_{0} t+\psi_{n}\right)
$$

where $\omega$ is the meshing frequency.

Every harmonic component of dynamic loads respectively are applied in the gearbox according to Table. 5, frequency responses of equivalent displacement are obtained as Fig. 26a and Fig. 27a.

To finally get the harmonic response under the real load, harmonic response results of all frequency components are superimposed as Eq. (35). 
Table 4. The parameters of herringbone gearbox.

\begin{tabular}{||c|c|c||c|c||}
\hline \multicolumn{3}{|c||}{ Gearbox } & \multicolumn{2}{c|}{ Lubrication oil } \\
\hline $\begin{array}{c}\text { Modulus of elasticity } \\
{\left[\mathrm{N} / \mathrm{m}^{2}\right]}\end{array}$ & Poisson's ratio & $\begin{array}{c}\text { Density } \\
{\left[\mathrm{kg} / \mathrm{m}^{3}\right]}\end{array}$ & $\begin{array}{c}\text { Acoustic velocity } \\
{[\mathrm{m} / \mathrm{s}]}\end{array}$ & $\begin{array}{c}\text { Density } \\
{\left[\mathrm{kg} / \mathrm{m}^{3}\right]}\end{array}$ \\
\hline \hline $2.06 \times 10^{11}$ & 0.3 & $7.8 \times 10^{3}$ & $1.53 \times 10^{3}$ & $8.8 \times 10^{2}$ \\
\hline
\end{tabular}

Table 5. Harmonic amplitudes and phase angles of dynamic load.

\begin{tabular}{||c|c|c|c||}
\hline $\begin{array}{c}\text { Frequency } \\
\text { components }\end{array}$ & $\begin{array}{c}\text { Static load } \\
P_{0}[\mathrm{~N}]\end{array}$ & $\begin{array}{c}\text { Amplitude } \\
A_{n}[\mathrm{~N}]\end{array}$ & $\begin{array}{c}\text { Phase angle } \\
\psi_{n}\left[{ }^{\circ}\right]\end{array}$ \\
\hline \hline $1 \times \omega_{0}$ & & 31.9 & 11.3 \\
$2 \times \omega_{0}$ & -2795 & 65.8 & -21.6 \\
$3 \times \omega_{0}$ & & 6.78 & 45.2 \\
\hline
\end{tabular}
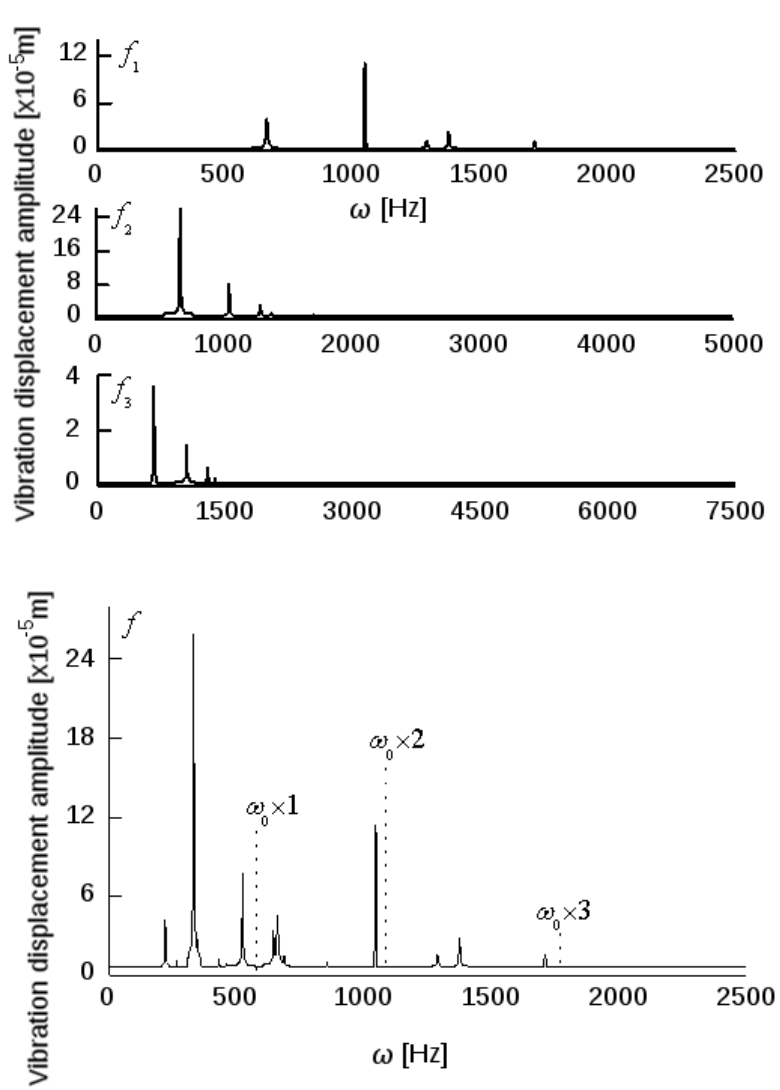

Figure 26. Vibration displacement harmonic response of point $R_{P 1}$.

$$
f(\omega)=f_{1}(\omega)+f_{2}(2 \omega)+f_{3}(3 \omega)
$$

From the results of Fig. 26b and Fig. 27b, it can be shown that the tooth meshing frequency did not excite the resonance of the herringbone gearbox, and this complies with the vibration design requirement. Furthermore, the resonance amplitude near twice meshing teeth frequency is larger than which is close to other frequency components in the point of RP1, and then in the point of RP3, the amplitude value near meshing frequency is the biggest.

\subsection{Transient Analysis Under Dynamic Loads}

The inner wall of the bearing hole is rigidly coupled with the centre reference point of the corresponding bearing hole. And the time-varying dynamic loads respectively are applied to each centre reference point by the APDL program. The FE
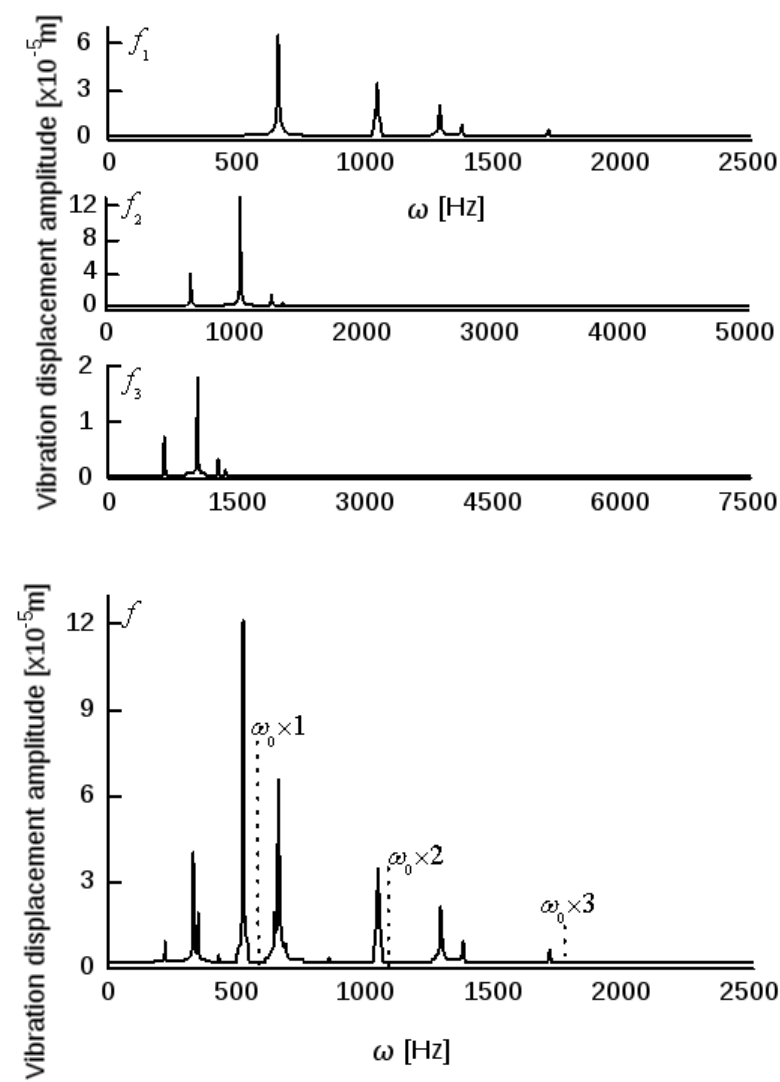

Figure 27. Vibration displacement harmonic response of point $R_{P 3}$.

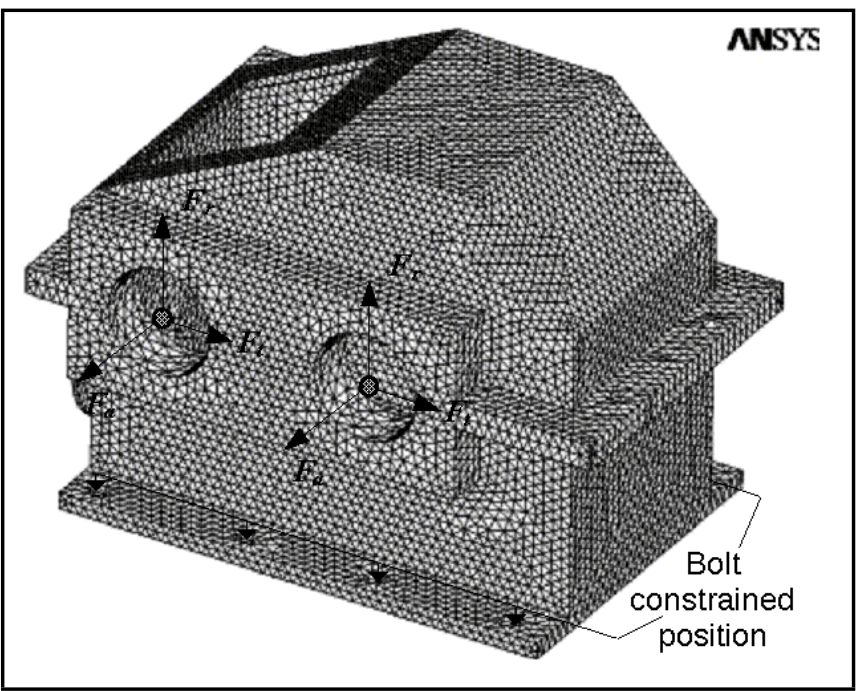

Figure 28. Vibration displacement harmonic response of point $R_{P 3}$.

model with external loads and actual constraints is shown in Fig. 28.

To get steady dynamic response of herringbone gearbox structure under complicated dynamic load excitation, solving the model by ANSYS transient analysis module until conform to the convergence condition as: 


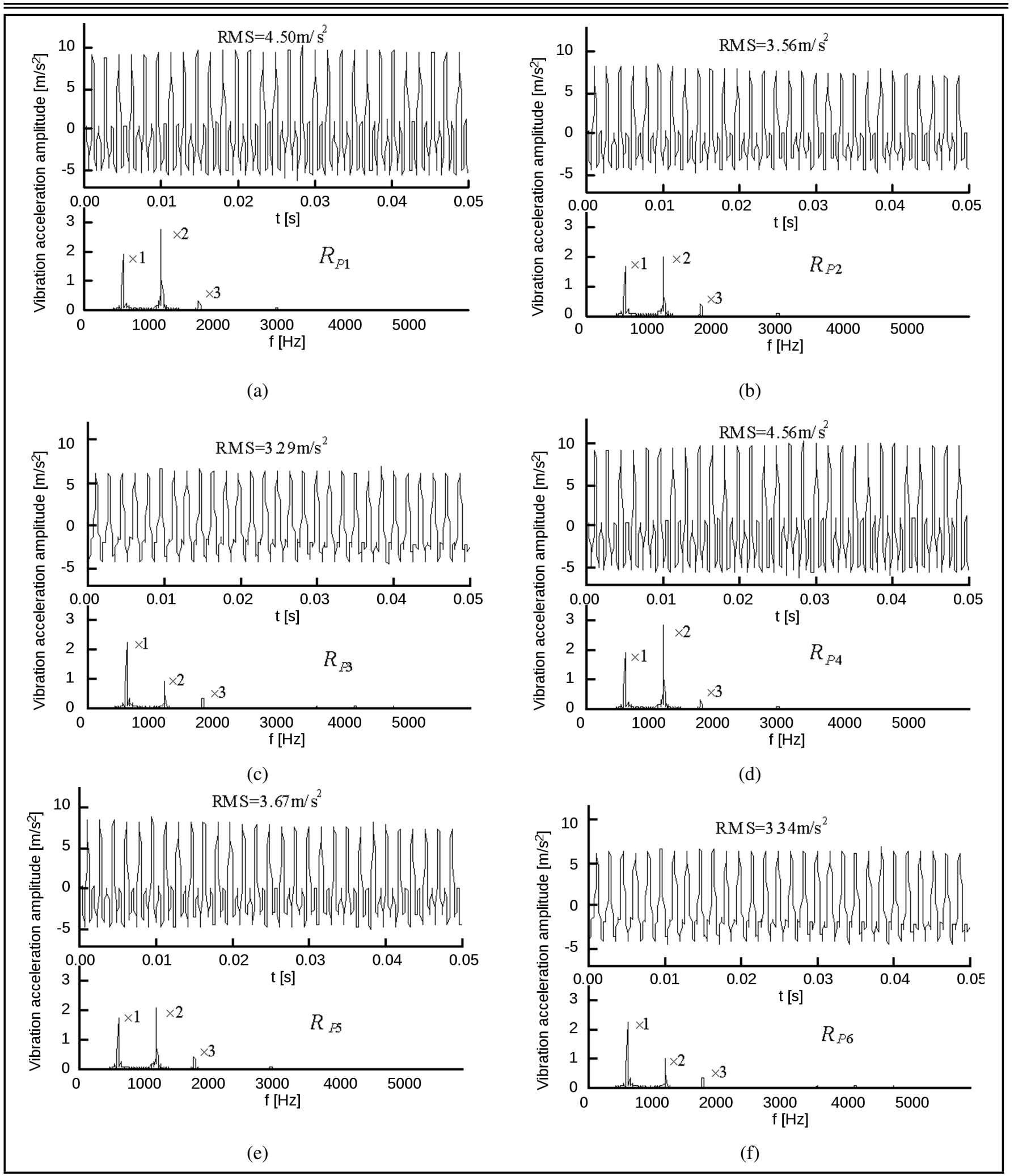

Figure 29. Vertical acceleration diagram of point $R_{P 1} \sim R_{P 6}$.

$$
\left|\frac{S_{i E}-S_{i S}}{S_{i E}}\right| \leq \varepsilon
$$

where $S_{i E}$ is the end displacement value of $i^{t h}$ solving cycle; $S_{i S}$ is the begin displacement value of ith solving cycle; $\epsilon$ is the maximum deviation that can be tolerated.

Setting for a period of 200 meshing cycles, and 50 steps among each mesh cycle, vertical vibration acceleration and frequency spectrum of concerned positions respectively are

shown in Fig. 29a-Fig. 29f. They are calculated in condition of $828 \mathrm{~N} \cdot \mathrm{m}$ and $2000 \mathrm{r} / \mathrm{min}$.

Vibration acceleration values in gearbox lugs $\left(R_{P 1}, R_{P 2}, R_{P 4}, R_{P 5}\right)$ of bearings are bigger than which in gearbox feet $\left(R_{P 3}, R P 6\right)$. Meanwhile, twice meshing frequency components account for the major part in the gearbox lugs of bearings, while components of meshing frequency account for the major part in the gearbox feet, and this is consistent with the conclusion in section 4.2. 


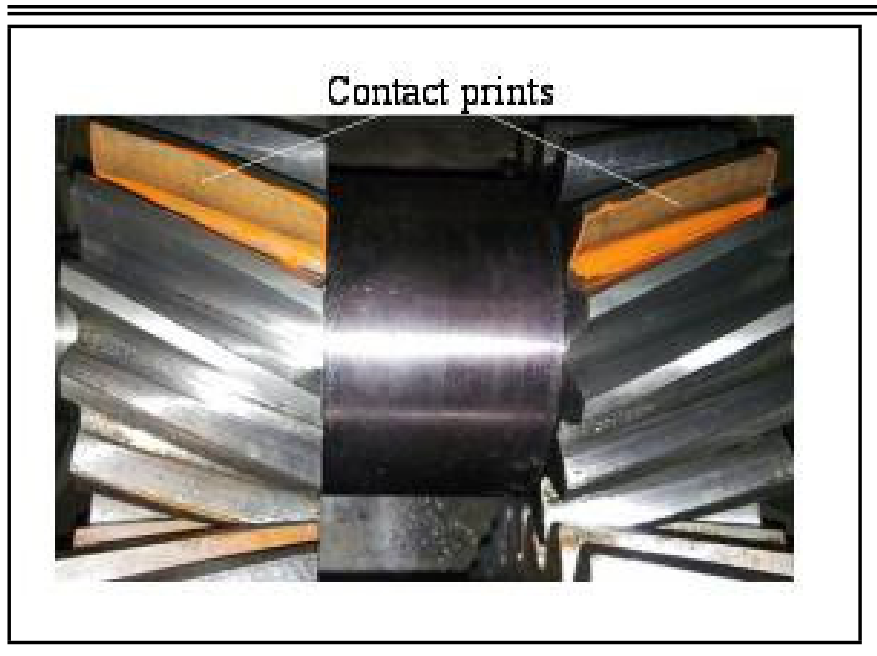

Figure 30. Meshing prints of experimental herringbone gear.

\section{EXPERIMENTAL MEASUREMENT AND RESULTS VERIFICATION}

To verify the results of theoretical analysis, experimental gear pairs were manufactured according to five grade precision. Running-in of the gear pairs was performed to achieve better meshing quality. As shown in Fig. 30, contact prints of the teeth surfaces indicate that teeth are in ideal contact condition.

\subsection{Test Equipment and the Scene Layout}

In view of the previous open power flow test bench with power consumption, high costs, serious waste of energy, and other shortcomings, the closed power flow test bench has been developed in recent decades, and has the advantages of low consumption and high stability. ${ }^{30}$ It is so called closed power flow that power transmission route is a closed loop, part consumption energy back feeding the system by other forms energy. Herringbone gear test bench site layout is shown in Fig. 31a.

The herringbone gear system is driven by direct-current motor, and the torques are applied in the elastic torsion shafts through the simple loader. In order to guarantee the agreement of transmission ratio and centre distance, the master gearbox is designed exactly the same as test box. The installation positions of rotating speed/torque sensor and Heidenhain optical encoders are shown in the following Fig. 31b and Fig. 31c. The model of Heidenhain optical encoders is ROD280, number of pulses per rev is 18000 , and the measurement accuracy can reach $\pm 5^{\prime \prime}$.

\subsection{Measuring Principle}

\subsubsection{Meshing relative acceleration test}

A pair of circular gratings respectively are installed in pinion and gear shafts. When the herringbone gear system operates stably, every instantaneous circumferential angle of herringbone gear are collected owing to PCI8502 acquisition card of Beijing Art Technology Development Co. Fig. 32 gives the output sine analogue signal of each channel. When rotating each reticle the grating outputs one complete sine wave signal. The signal of channel 0 corresponds with the rotation of pinion, and that of channel 1 corresponds with the rotation of gear. The sampling frequency of circular grating is $500 \mathrm{kHz}$.
To analyse the acquired signals, firstly take the zero-crossing detection method to count the number of samples in each sine wave $\left(A_{i} A_{i+1}, B_{i} B_{i+1}\right)$, and then calculate the radian value by amplitude of cosine function in Fig. 32. Time continuous angles can be obtained by Eq. (37).

$$
\varphi\left(t_{i, j}\right)=\varphi\left(t_{i, j-1}\right)+\frac{360}{N} \cdot\left(\frac{\left|\theta\left(t_{i, j}\right)-\theta\left(t_{i, j-1}\right)\right|}{2 \pi}\right) ;
$$

where $\varphi\left(t_{i j}\right)$ is the angle value for the $i^{t h}$ sine wave in the $j^{t h}$ sampling time; $N$ is the grating circumferential groove number; $\Theta\left(t_{i j}\right)$ is the corresponding radian value for the ith sine wave in the $j^{\text {th }}$ sampling time.

The meshing line displacement can be attained according to angular displacement multiplied by the respective base circle radius in Fig. 33. The relative vibration acceleration can be got through second derivative as shown in Eq. (38).

$$
a_{12}(t)=\frac{\pi}{180} \cdot\left(\left(\varphi_{2}-\varphi_{20}\right) \cdot r_{b 1}-\left(\varphi_{1}-\varphi_{10}\right) \cdot r_{b 2}\right)^{\prime \prime}
$$

where $\varphi_{1}$ is the actual rotation angle of pinion; $\varphi_{2}$ is the actual rotation angle of gear; $\varphi_{10}$ is the initial rotation angle of pinion; $\varphi_{20}$ is the initial rotation angle of gear; $r_{b 1}$ is the base circle radius of pinion; $r_{b 2}$ is the base circle radius of gear.

\subsubsection{Vibration acceleration test of gearbox}

For the specific position of six measuring points on gearbox refer to Fig. 25. The accelerometer voltage signals are collected into notebook PC through signal-harvesting device $(\mathrm{M}+\mathrm{P})$ for subsequent filtering, analysis and other processing procedure. The sampling frequency of accelerometer is $16 \mathrm{KHz}$.

\subsection{Comparative Analysis of Test Results}

Dynamic transmission error is finally obtained by the above principle of the circular grating measurements, and dynamic transmission error is specified in arc seconds. Fig. 34 is in condition of $828 \mathrm{~N} \cdot \mathrm{m}, 2000 \mathrm{r} / \mathrm{min}$.

It is clearly seen frequency components including gear shaft rotation frequency $(13.3 \mathrm{~Hz})$, pinion shaft rotation frequency $(34.5 \mathrm{~Hz})$, meshing frequency $(566.7 \mathrm{~Hz})$, and twice meshing frequency (1133.4 Hz) in Fig. 34.

The relative vibration acceleration is finally obtained by Eq. (38) in Fig. 35.

Total RMS value over all frequency of the herringbone gear meshing vibration is $32.13 \mathrm{~m} / \mathrm{s}^{2}$, and the twice meshing frequency is significant with the value of $23.15 \mathrm{~m} / \mathrm{s}^{2}$, which is in accordance with the theoretical result.

Fig. 36 shows the vibration acceleration respond with the various input rotational speeds, and the maximum rotational speed is restricted within $2500 \mathrm{r} / \mathrm{min}$ due to experimental conditions.

Theoretical data and experimental data are in agreement, and the visible acceleration peak occurred in the $1 / 3$ resonance rotational speed.

Fig. 37a-Fig. 37f are the vertical vibration acceleration in herringbone gearbox reference points of $R_{P 1}-R_{P 6}$.

As for the theoretical analysis, the twice meshing frequency components of acceleration spectrum account for the major 


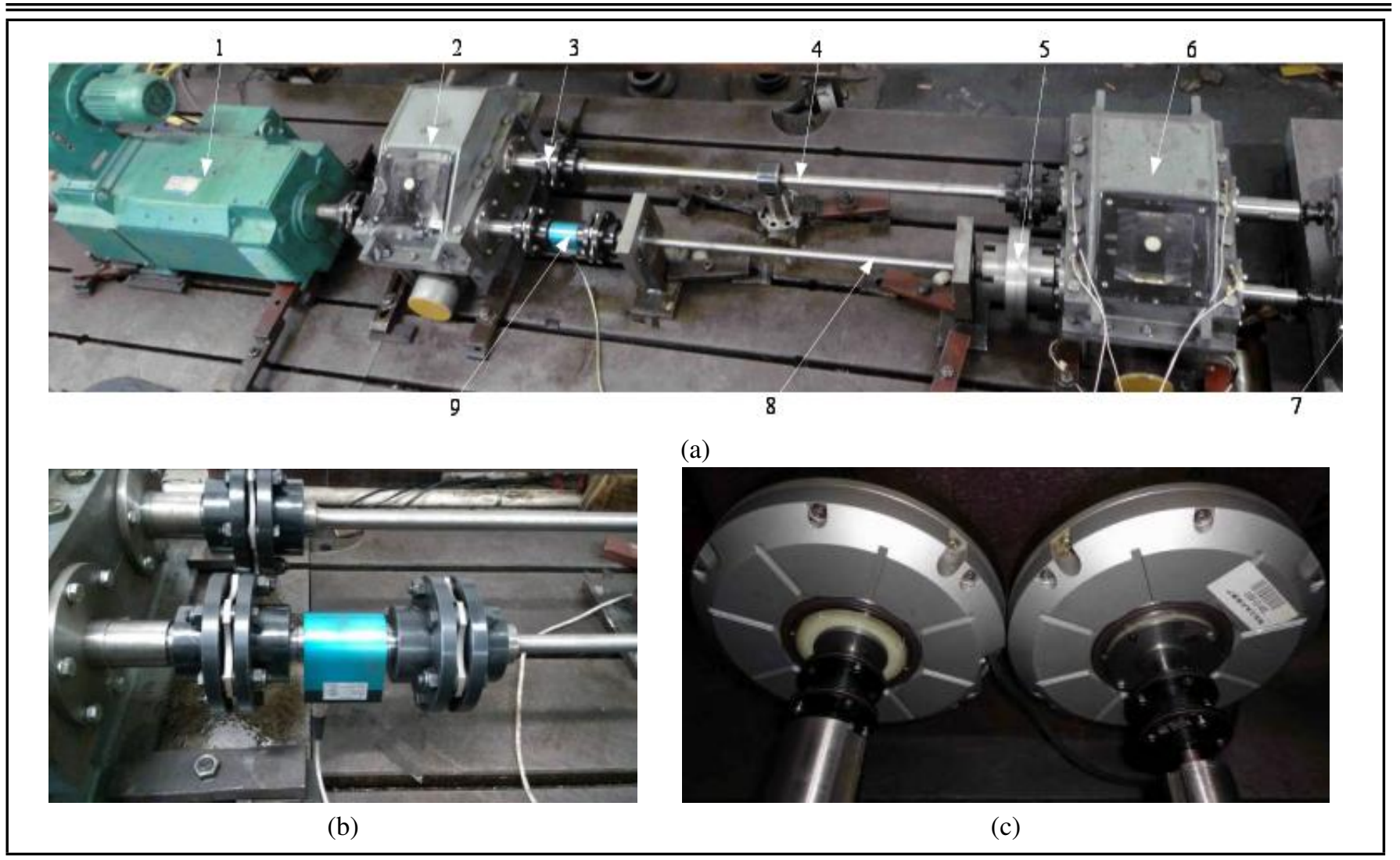

Figure 31. Herringbone gear test rig of closed power flow. 1. DC motor; 2. the master gearbox; 3.coupling; 4.low-speed torsion shaft; 5.Simple loader; 6.test box; 7. Heidenhain optical encoders; 8.high-speed torsion shaft; 9.rotating speed and torque sensor.

Table 6. Vibration acceleration of the herringbone gear system.

\begin{tabular}{|c|c|c|c|c|c|c|c|}
\hline \multirow{2}{*}{ Parameters } & \multicolumn{3}{|c|}{ Theoretical data $\left[\mathrm{m} / \mathrm{s}^{2}\right]$} & \multicolumn{3}{|c|}{ Experimental data $\left[\mathrm{m} / \mathrm{s}^{2}\right]$} & \multirow{2}{*}{$\begin{array}{c}\text { Maximum deviation } \\
{[\%]}\end{array}$} \\
\hline & $621 \mathrm{~N} \cdot \mathrm{m}$ & $828 \mathrm{~N} \cdot \mathrm{m}$ & $1035 \mathrm{~N} \cdot \mathrm{m}$ & $621 \mathrm{~N} \cdot \mathrm{m}$ & $828 \mathrm{~N} \cdot \mathrm{m}$ & $1035 \mathrm{~N} \cdot \mathrm{m}$ & \\
\hline Meshing acceleration & 25.10 & 29.38 & 34.23 & 28.31 & 32.13 & 36.54 & 11.3 \\
\hline$R_{P 1}$ & 3.85 & 4.50 & 5.23 & 4.43 & 5.18 & 6.02 & 13.1 \\
\hline$R_{P 2}$ & 3.10 & 3.56 & 4.14 & 3.58 & 4.12 & 4.80 & 15.4 \\
\hline$R_{P 3}$ & 2.81 & 3.29 & 3.83 & 3.10 & 3.63 & 4.22 & 9.37 \\
\hline$R_{P 4}$ & 3.89 & 4.56 & 5.31 & 4.48 & 5.21 & 6.08 & 13.2 \\
\hline$R_{P 5}$ & 3.14 & 3.67 & 4.27 & 3.65 & 4.29 & 4.91 & 14.4 \\
\hline$R_{P 6}$ & 2.85 & 3.34 & 3.89 & 3.16 & 3.86 & 4.31 & 13.4 \\
\hline
\end{tabular}

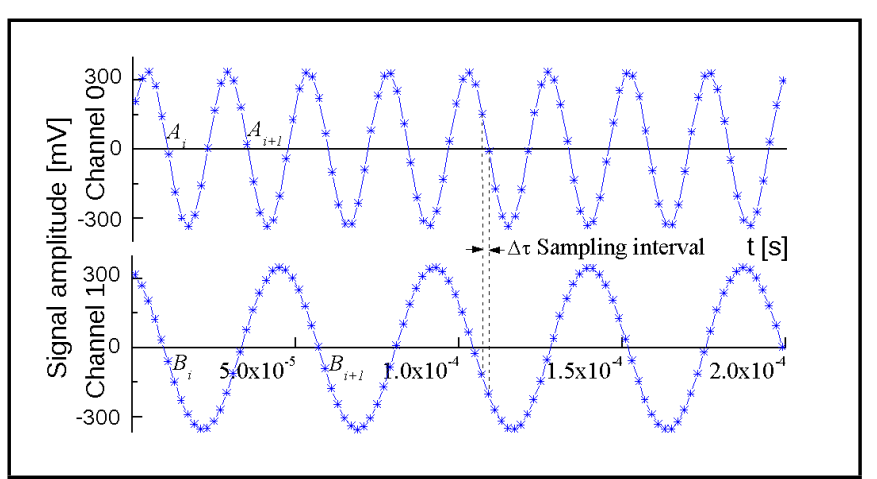

Figure 32. Sine wave signals of grating encoder.

part in points of $R_{P 1}, R_{P 2}, R_{P 4}, R_{P 5}$, and components of meshing frequency account for the major part in points of $R_{P 3}$, $R_{P 6}$.

For a more comprehensive verification of herringbone gear vibration, all positions of theoretical vibration values are shown in Table. 6 for comparison with the experimental measurements.

The maximum relative deviation between the theoretical results and the experimental data is less than $15 \%$ according to

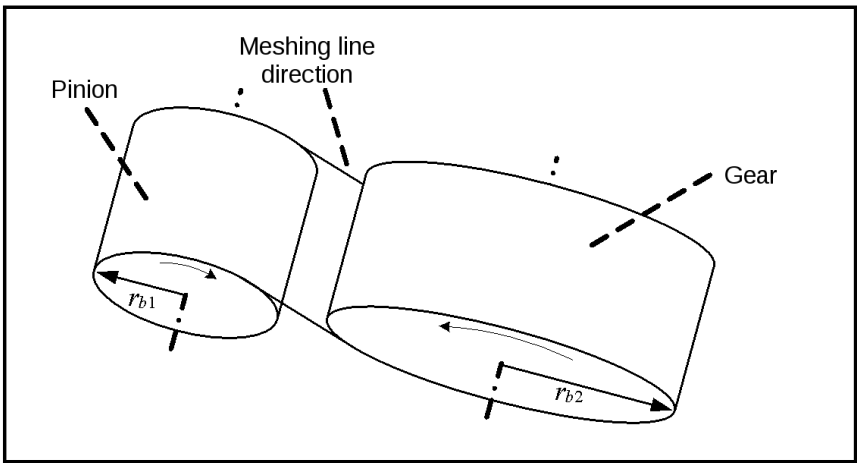

Figure 33. Measuring principle of the relative vibration.

Table. 6.

In herringbone gear transmission system, vibration acceleration between the meshing teeth is significantly greater than the gearbox body, and vibration acceleration values in gearbox lugs of bearing $\left(R_{P 1}, R_{P 2}, R_{P 4}, R_{P 5}\right)$ are slightly larger than that in gearbox feet $\left(R_{P 3}, R_{P 6}\right)$. This is consistent with the characteristics of vibration transfer process from meshing teeth to gear shafts, to supporting bearings, and finally to gearbox 


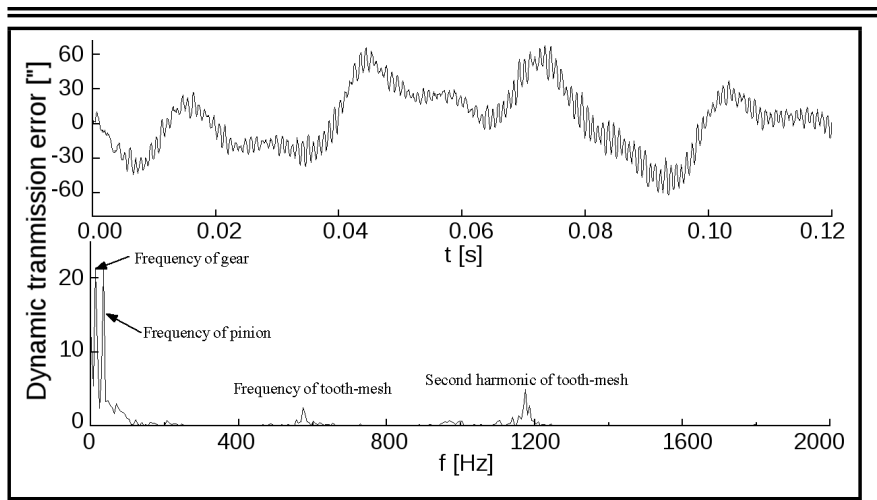

Figure 34. Dynamic transmission error of herringbone gear.

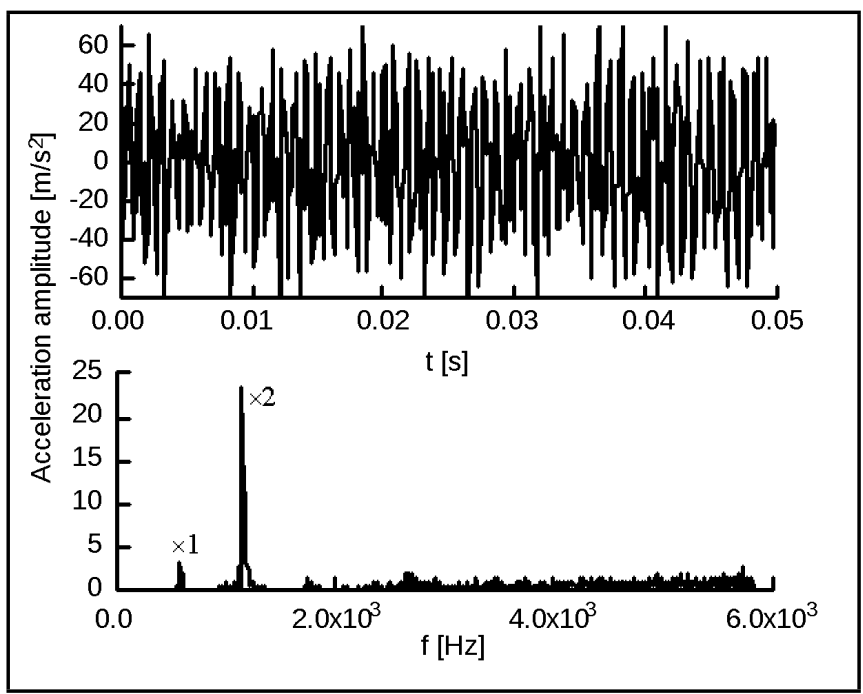

Figure 35. Meshing relative vibration acceleration of experiment.

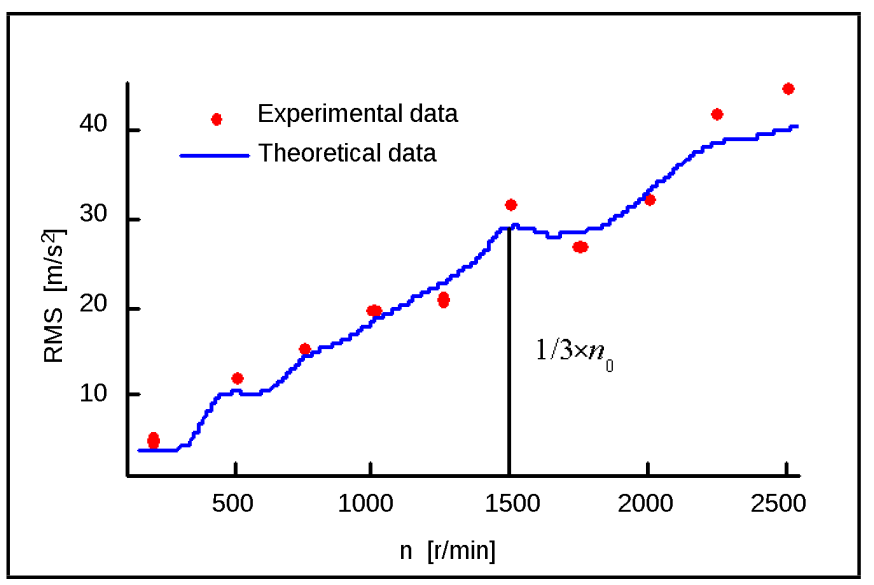

Figure 36. Meshing vibration acceleration of different rotation speeds.

\section{CONCLUSION}

This paper has provided a series of appropriate models to study the dynamic characteristics in herringbone gear transmission system. The models consist of a twelve-degrees-offreedom discrete vibration model of herringbone gear pairs, a transfer model of rolling element bearings, and a FE model of gearbox. The excitations including varying-time meshing stiffness, corner meshing impact, and teeth friction forces. Vibration effects analyses of each excitation factor were performed by solving the herringbone gear dynamic system under different excitations.
An example set of analyses were performed to point various unique features of herringbone gear transmission system, and the dynamic forces in the gear contact surfaces and on the bearings have been calculated for various speeds and torques of the gear pairs. Experimental studies were used to validate the theoretical predictions in this paper. The similarity and consistency between simulated and measured signals suggest that the model can be used efficiently to analyse the vibration transmission process of actual herringbone gear system. The experimental data also reveals that vibration measurement method by Heidenhain optical encoders and Altai acquisition card is reasonable and feasible under the given operating condition.

The method presented in this study can not only conveniently predict the dynamic behaviour of the system but also restrict the herringbone gear system vibration and noise in a small range by adjusting the parameters of gear pairs, bearings and gearbox, but it mainly focuses on the source and transmission process of the meshing noise, and does not rigorously explore the effects of bearing nonlinear oil-film force on gear system vibration transmission. Future work should address a more accurate model of rolling element bearings by considering the nonlinear oil-film force used to estimate the gear vibration transmission. And herringbone gear vibration transmission model supporting with sliding bearing also should be given to enrich the theory.

\section{FUNDING}

This work was supported by National Natural Science Foundation of China (No. 51705204); China Postdoctoral Science Foundation (No. 2017M611710); National Key R \& D Plan (No. 2017YFB0103200).

\section{REFERENCES}

$1 \mathrm{He}, \mathrm{R} ., \mathrm{Xu}, \mathrm{Y}$. Q. Shift schedule of parallel hybrid electric vehicles under hybrid driving mode. Journal of JiangSu University, 37(6): 657-662, (2016). https://dx.doi.org/10.3969/j.issn.1671-7775.2016.06.007

2 Chen, L., Ren, H., Yuan, C. C., and Wang, S. H. Design and simulation power system for hybrid electric vehicles with wheel motors. Journal of JiangSu University, 36(1): 006-010, (2015). https://dx.doi.org/10.3969/j.issn.16717775.2015.01.002

3 Jiang, K. J., He, R., Liu, W. G., and Shu, C. Engine control method of double rotor motor power coupling system. Journal of JiangSu University, 36(6): 627-633, (2015). https://dx.doi.org/10.3969/j.issn.1671-7775.2015.06.002

4 Özgüven, H. N., \& Houser, D. R. Mathematical models used in gear dynamicsa review. Journal of Sound and Vibration, 121(3): 383-411, (1988). https://dx.doi.org/10.1016/s0022-460x(88)80365-1

$5 \mathrm{Wu}$, S., Zuo, M. J., \& Parey, A. Simulation of spur gear dynamics and estimation of fault growth. Journal of Sound and Vibration, 317(3): 608-624, (2008). https://dx.doi.org/10.1016/j.jsv.2008.03.038 


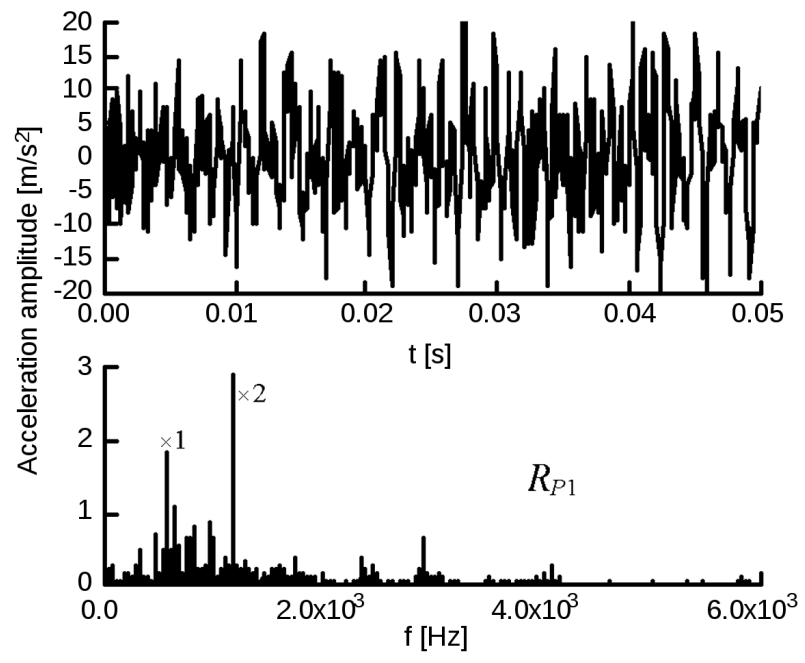

(a)

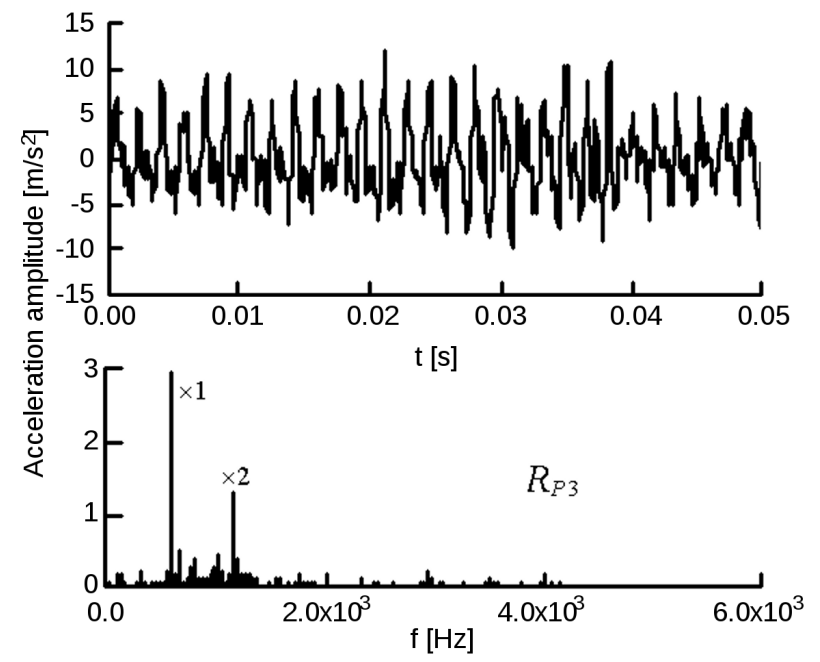

(c)

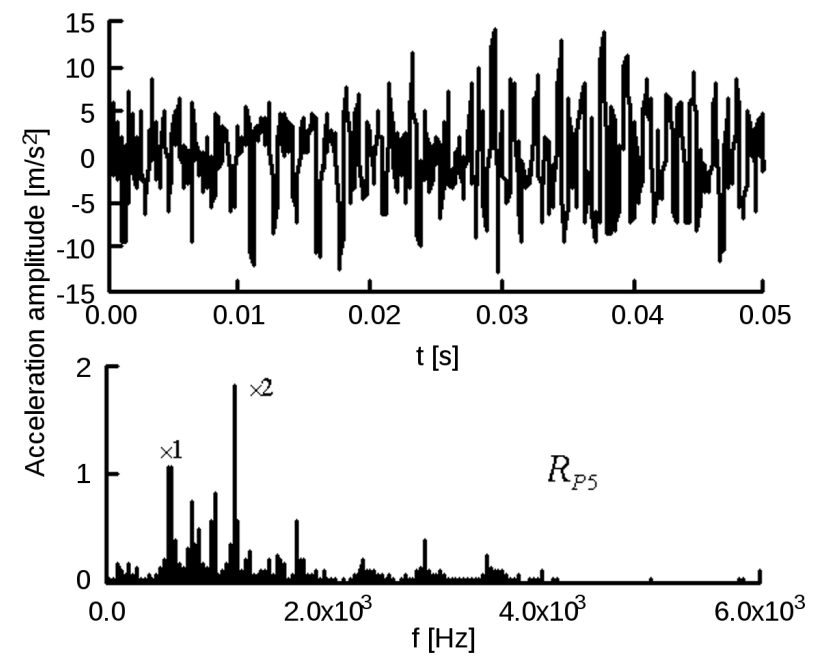

(e)

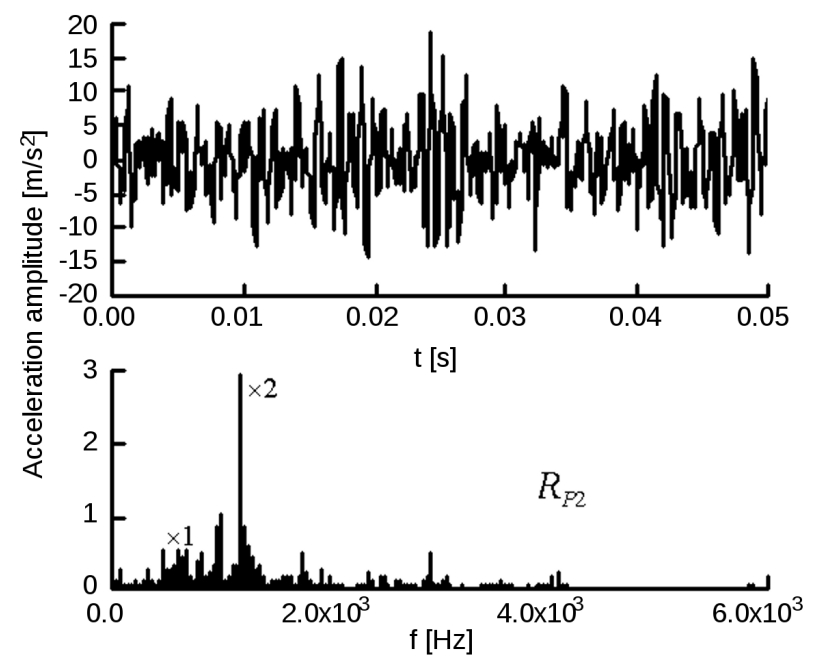

(b)

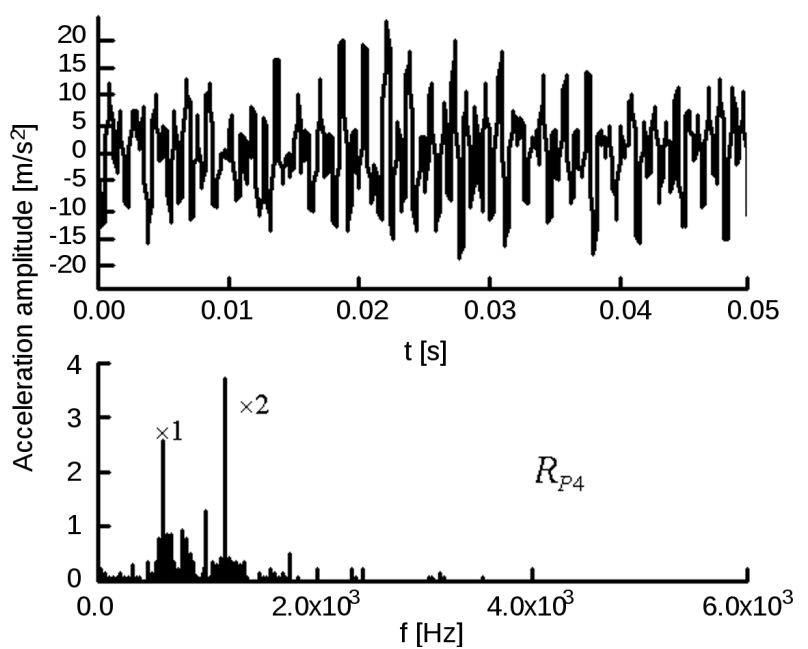

(d)

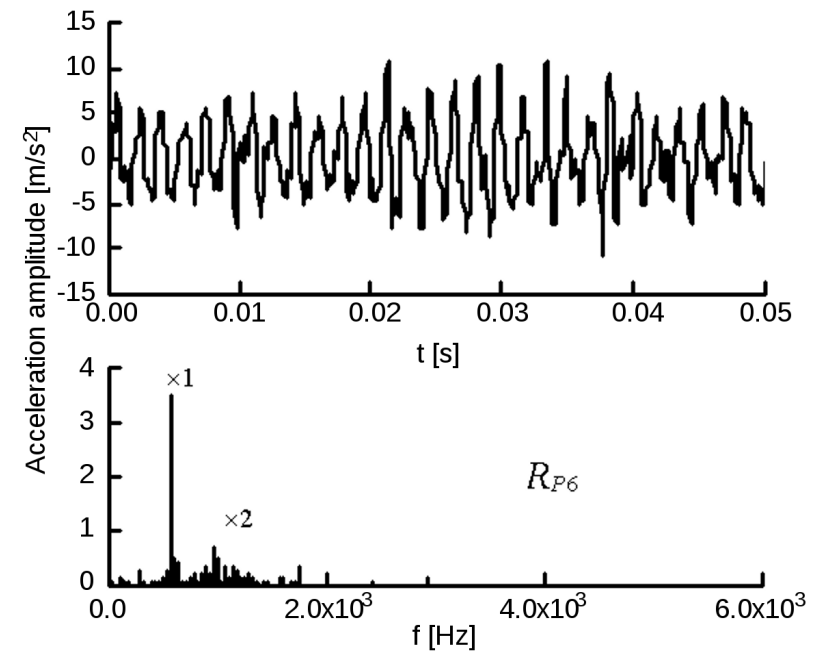

(f)

Figure 37. Vertical vibration acceleration of $R_{P 1} \sim R_{P 6}$.

6 Huang, K. J., \& Liu, T. S. Dynamic analysis of a spur gear by the dynamic stiffness method. Journal of Sound and Vibration, 234(2): 311-329, (2000). https://dx.doi.org/10.1006/jsvi.1999.2869

7 Theodossiades, S., and Natsiavas, S. Non-linear dynamics of gear-pair systems with periodic stiffness and backlash. Journal of Sound and vibration, 229(2): 287-310, (2000). https://dx.doi.org/10.1006/jsvi.1999.2490

8 Kang, C. H., Hsu, W. C., Lee, E. K., and Shiau, T. N. Dynamic analysis of gear-rotor system with vis- 
coelastic supports under residual shaft bow effect. Mechanism and Machine Theory, 46(3): 264-275, (2011). https://dx.doi.org/10.1016/j.mechmachtheory.2010.11.011

9 Shabaneh, N. H., and Zu, J. W. Dynamic analysis of rotorshaft systems with viscoelastically supported bearings. Mechanism and machine theory, 35(9): 1313-1330, (2000). https://dx.doi.org/10.1016/s0094-114x(99)00078-6

10 Li, R., Yang, C., Lin, T., Chen, X., and Wang, L. Finite element simulation of the dynamical behavior of a speed-increase gearbox. Journal of materials processing technology, 150(1): 170-174, (2004). https://dx.doi.org/10.1016/j.jmatprotec.2004.01.030

11 Dabrowski, D., Adamczyk, J., and Plascencia, H. M. A multi-body model of gears for simulation of vibration signals for gears misalignment. Diagnostyka, 2(62): 15-22, (2012). http://yadda.icm. edu.pl/yadda/element/bwmetal.element. baztech-article-BAR0-0068-0053

12 Hambric, S. A., Shepherd, M. R., Campbell, R. L., and Hanford, A. D. Simulations and measurements of the vibroacoustic effects of replacing rolling element bearings with journal bearings in a simple gearbox. Journal of Vibration and Acoustics, 135(3): 031012, (2013). https://dx.doi.org/10.1115/1.4024087

13 Okamura, H., Shinno, A., Yamanaka, T., Suzuki, A., and Sogabe, K. Simple modeling and analysis for crankshaft three-dimensional vibrations, part 1: background and application to free vibrations. Journal of vibration and acoustics, 117(1): 70-79, (1995). https://dx.doi.org/10.1115/1.2873869

14 Park, Y. J., Lee, G. H., Song, J. S., and Nam, Y. Y. Characteristic Analysis of Wind Turbine Gearbox Considering Non-Torque Loading. Journal of Mechanical Design, 135(4): 044501, (2013). https://dx.doi.org/10.1115/1.4023590

15 Qin, D., Lim, T. C., and Wang, J. Flexible multibody dynamic modeling of a horizontal wind turbine drivetrain system. Journal of Mechanical Design, 131(11): 114501, (2009). https://dx.doi.org/10.1115/1.3211094

16 Khabou, M. T., Bouchaala, N., Chaari, F., Fakhfakh, T., and Haddar, M. Study of a spur gear dynamic behavior in transient regime. Mechanical Systems and Signal Processing, 25(8): 3089-3101, (2011). https://dx.doi.org/10.1016/j.ymssp.2011.04.018

17 Velex, P. On the modelling of spur and helical gear dynamic behaviour. arXiv preprint arXiv:1204.2636, (2012). https://dx.doi.org/10.5772/36157

18 Qian, M. B., Yu, G. H., Zhang, X. F., and Chu, B. B. Design method and fatigue strength analysis of eccentric-noncircular gear transmission mechanism. Journal of JiangSu University, 37(1): 44-48, (2016). https://dx.doi.org/10.3969/j.issn.1671-7775.2016.01.009

19 Zhang Y and Fang Z. Analysis of tooth contact and load distribution of helical gears with crossed axes.
Mechanism and machine theory, 34(1): 41-57, (1999) https://dx.doi.org/10.1016/s0094-114x(98)00006-8

20 Zhou, C., Tang, J., and Zhong, Z. Corner contact and impact friction of gear drive. Chinese Journal of Mechanical Engineering, 44(3): 75-81, (2008). https://dx.doi.org/10.3901/jme.2008.03.075

$21 \mathrm{Wu}$, S., and Cheng, H. S. A friction model of partialEHL contacts and its application to power loss in spur gears. Tribology Transactions, 34(3): 398-407, (1991). https://dx.doi.org/10.1080/10402009108982050

22 Stokes, A. Gear handbook: design and calculations. Society of Automotive Engineers, (1992). https://dx.doi.org/10.1016/0301-679x(93)90100-f

23 Souza, S. L. T., Caldas, I. L., Viana, R. L., and Batista, A. M. Noise-induced basin hopping in a gearbox model. Chaos, Solitons \& Fractals, 26(5): 1523-1531, (2005). https://dx.doi.org/10.1016/j.chaos.2005.04.033

24 Chai, S., Guo, M., Xu, S. H., Zhang, Q., and Gang, X. Y. Finite element models for vehicle leaf spring suspensions. Journal of JiangSu University, 36(1): 016-022, (2015). https://dx.doi.org/10.3969/j.issn.1671-7775.2015.01.004

${ }^{25}$ Chen, J. M., Wang, Y. Y., Sun, M. Y., and Kang, Z. J. Comprehensive operation optimization of distribution network based on improved bacterial colony chemotaxis algorithm. Journal of JiangSu University, 36(1): 087-092, (2015). https://dx.doi.org/10.3969/j.issn.1671-7775.2015.01.016

26 Cai, H., Zhu, H. Q., and Wu, X. A fast determination method of DG locating and sizing based on artificial neural network algorithm. Journal of JiangSu University, 37(3): 309-314, (2016). https://dx.doi.org/10.3969/j.issn.16717775.2016.03.010

27 Oehlmann, H., Brie, D., Tomczak, M., and Richard, A. A method for analysing gearbox faults using timefrequency representations. Mechanical Systems and Signal Processing, 11(4): 529-545, (1997). https://dx.doi.org/10.1006/mssp.1996.0093

28 Choy, F. K., Zakrajsek, J. J., Townsend, D. P., Ruan, Y. F., and Tu, R. K. Modal analysis of multistage gear systems coupled with gearbox vibrations. Journal of Mechanical Design, 114(3): 486-497, (1992). https://dx.doi.org/10.1115/1.2926577

29 Moaveni, S. Finite element analysis: theory and application with ANSYS. State \& Local Government Review, 42(2): 176-187, (2010). https://dx.doi.org/10.1016/s08926875(99)90030-4

${ }^{30}$ Cho, S., Choi, J., Jin, H. C., \& Rhim, S. Numerical estimation of dynamic transmission error of gear by using quasi-flexible-body modeling method. Journal of Mechanical Science \& Technology, 29(7), 2713-2719, (2015). https://dx.doi.org/10.1007/s12206-015-0519-x

31 Tuma, J. Vehicle gearbox noise and vibration: measurement, signal analysis, signal processing and noise reduction measures. Gastroenterology, 144(2): 381-391, (2014). https://dx.doi.org/10.1002/9781118797563 